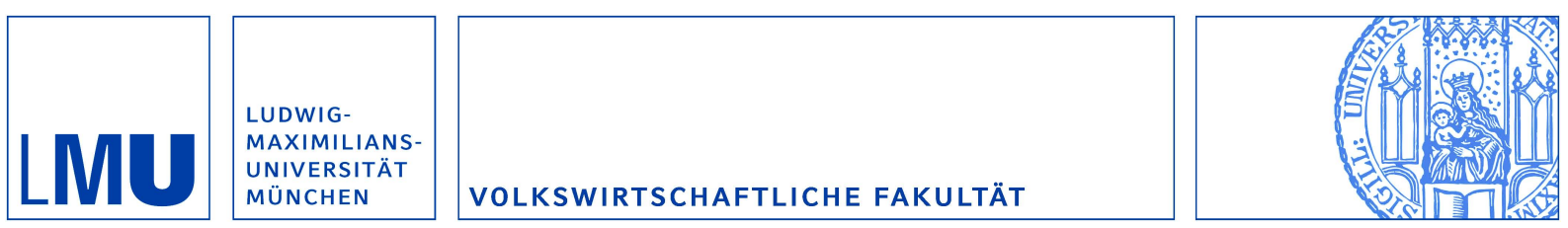

Appelt, Silvia:

Authorized Generic Entry prior to Patent Expiry: Reassessing Incentives for Independent Generic Entry

Munich Discussion Paper No. 2010-23

Department of Economics

University of Munich

Volkswirtschaftliche Fakultät

Ludwig-Maximilians-Universität München

Online at https://doi.org/10.5282/ubm/epub. 11476 


\title{
Authorized Generic Entry prior to Patent Expiry: Reassessing Incentives for Independent Generic Entry
}

\author{
Silvia Appelt* \\ Munich Graduate School of Economics, University of Munich
}

April 2010

\begin{abstract}
Patent holders frequently attempt to mitigate the loss of monopoly power by authorizing generic entry prior to patent expiry (early entry). Competition in off-patent pharmaceutical markets may be adversely affected if early entry substantially impairs the attractiveness of subsequent market entry. I examine generic entry decisions made in the course of recent patent expiries to quantify the impact of early entry on incentives for generic entry. Using unique micro data and accounting for the endogeneity of early entry, I estimate recursive bivariate probit models of entry. Drug markets' pre-entry revenues largely determine both independent generic entry and early entry decisions. Early entry in turn has no significant impact on the likelihood of generic entry. Original drug producers appear to authorize generic entry prior to loss of exclusivity primarily fueled by rent-seeking rather than strategic entry-deterrence motives.
\end{abstract}

Keywords: Generic Entry, Early Entry, Anticompetitive Practices. JEL Classification Numbers: L41, I11, O34, C35.

*Address: Kaulbachstr. 45, Room\# 308, 80539 Munich, Germany, telephone: +49-89-2180-5761; Mail to: MGSE, Kaulbachstrasse 45, 80539 Munich, Germany; E-mail: silvia.appelt@lrz.uni-muenchen.de.

I would like to thank seminar participants at the DRUID-DIME 2009 Winter Ph.D. Conference, at the CEPR 2009 Applied IO School, at the Annual CCC Conference 2009, at the EEA Annual Congress 2009, the EARIE Annual Conference 2009 and at the NBER Productivity Lunch Seminar (April 2010) for their helpful comments. I am deeply grateful to Dietmar Harhoff, Georg von Graevenitz, Joachim Winter, Ernst Berndt, Toke Reichstein and Georg Gebhardt for their advice and suggestions. Finally, I would like to thank Insight Health for providing data. All remaining errors are my own. 


\section{Introduction}

As blockbuster drugs lose patent protection and drug pipelines have run dry, "Big Pharma" seeks ways to limit profit erosion following generic entry. ${ }^{1}$ One increasingly common practice has become the introduction of a generic version of the original drug prior to the loss of exclusivity - expiry of patent or supplementary protection certificate $(\mathrm{SPC})^{2}-$, either through a subsidiary or licensee/supply partner (early entry). The increasing frequency of early entry has raised policy concerns (FTC, 2002; EUC, 2008; FTC, 2009; EUC, 2009). First-movers enjoy a sustainable competitive advantage over subsequent entrants (Caves et al., 1991; Grabowski and Vernon, 1992; Hollis, 2002), and anticipated early entry may reduce incentives for generic entry and put at risk drug expenditure savings. The prevailing assumption is that generic firms anticipate early entry based on drug markets' characteristics and past experiences. A few empirical studies (Hollis, 2003; Reiffen and Ward, 2007; Berndt et al., 2007a,b) investigate the impact of early entry - exogenously given - on generic entry, arriving at different conclusions. Berndt et al. (2007a) concede that authorized generic entry prior to patent expiry may reduce incentives to generic firms, yet they emphasize that there is no comprehensive empirical evidence based on recent data that would show early entry to have had a delaying or deterring effect on generic entry. Except for the study by Berndt et al. (2007a), peer-reviewed analyses rely on data from the late 80s, early and mid 90s. This study is the first to employ recent micro data to examine generic and early entry decisions.

The previous debate has largely centered on the effect of anticipated authorized generic entry on generic firms' incentives to pursue paragraph IV challenges prior to patent expiry. In the U.S., the first generic manufacturer to file for market approval with a successful paragraph IV certification (claim of patent non-infringement or patent invalidity) is granted a 180-day exclusivity period where no other generic firm (except for the authorized generic) is entitled to market the same version of the drug. If authorized generic entry drastically lowered generic firms' incentives to file paragraph IV certifications, generic entry could be delayed. The 180-day exclusivity period is an institutional feature specific to the U.S. phar-

\footnotetext{
${ }^{1}$ The Economist, January $24^{\text {th }} 2008$ : "The bitterest pill".

${ }^{2}$ A certificate that allows for an extension of market exclusivity for up to five years after patent protection which - depending on the life cycle of the drug - is granted by the national patent office.
} 
maceutical market. Moreover, only a fraction of generic applications seek entry prior to patent expiry. ${ }^{3}$ Whether early entry broadly impaired generic entry in recent years, remains an open question. Providing a complete answer to this question requires the modeling of original drug producers' early entry decisions which are endogenous. Original drug producers appear to decide on early arrangements on a case-by-case basis most often in the year prior to loss of exclusivity (EUC, 2009). Hollis and Liang (2006); FTC (2009) emphasize that set of drug markets experiencing early entry is not a random selection of markets.

This study accounts for the endogeneity of early entry and provides comprehensive empirical evidence on the impact of early entry on generic entry decisions made in the course of recent patent expiries. The analysis relies on a unique micro data set comprising German pharmaceutical market and exclusivity data (patents and SPCs) for the German pharmaceutical market, the second largest generic drug market in the world, experiencing the largest number of early entries of all European generic drug markets between 2000 and 2007 (EUC, 2009). 75 substances $^{4}$ lost exclusivity (patent or SPC protection) between 2002 and 2007. By the end of 2007, 87 generic firms entered in 48 markets $^{5}$, resulting in a total of 724 market entries $^{6}$ by independent generic firms. Of the 48 drug markets experiencing generic entry, 16 markets were affected by early entry from 2002 to 2007. Early entry occurred on average four months prior to loss of exclusivity. I estimate univariate and recursive bivariate probit models of entry to quantify the impact of early entry. Treating early entry as exogenous (univariate probit model) may give rise to a selection problem and inconsistent estimates if early entry occurs in markets that are more attractive than given market characteristics suggest, or in other words, if there is a spurious correlation between early entry and generic entry decisions. Bivariate probit estimates indicate that early entry decisions are endogeneous. The identification strategy in the bivariate probit model relies on the assumption of normality and the fact that I model sequential entry decisions. Exclusion restrictions are

\footnotetext{
${ }^{3}$ From 1998 to $2000,20 \%$ of generic applications included a paragraph IV certificate (FTC, 2002).

${ }^{4}$ Throughout the paper the term substance is equivalently used for mono-substance, i.e. a substance that contains one active ingredient only. As the allocation of all relevant patents and supplementary protection certificates to mono-substances is delicate, the analysis is confined to mono-substances.

${ }^{5}$ Other studies report similar rates of generic entry, e.g. Magazzini et al. (2004).

${ }^{6}$ As one firm typically enters in more than one market, this yields 724 generic entries in total.
} 
not necessarily required to achieve identification in recursive bivariate probit models (Wilde, 2000; Greene, 2008). I do impose one exclusion restriction to improve identification. As early entry decisions are arguably motivated by pioneers' financial distress, I add a count of each original drug producers' further losses of exclusivity between 2002 and 2007 as an instrumental variable to the early entry equation. As Evans and Schwab (1995), I provide tentative empirical evidence on the suitability of the instrument, showing that the instrumental variable has no significant effect on generic entry decisions. Determining the average marginal effect of early entry in the bivariate probit model, I compute the average change in the probability of generic entry conditional on early entry having and having not occured. Standard errors are computed using the delta-method (Papke and Wooldridge, 2005). Regardless of the identifying assumption made, early entry turns out to have no significant impact on the probability of generic entry. Originators appear to authorize generic entry prior to loss of exclusivity to extract generic profits rather than to deter generic entry. Drugs' pre-entry market size has a significant, and comparably the strongest impact on generic entry decisions. A $1 \%$ increase in pre-entry revenues induces on average a $14-18 \%$ increase in the likelihood of generic entry. Furthermore, I find that the number of off-patent substitute active ingredients has a negative impact on entry, whereas the length of the exclusivity period and firms' therapeutic and drug form experience influence generic entry decisions positively.

The organization of the paper is as follows: Section 2 provides relevant industry information. Section 3 reviews the literature on early entry. Section 4 describes the data, and Section 5 specifies the empirical implementation. Section 6 presents and discusses the empirical findings. Concluding remarks follow in Section 7.

\section{Industry Background}

With a market size of $€ 4.5 \mathrm{Bn}$. and a generic penetration $\left(\right.$ efficiency $^{7}$ ) rate of about $20 \%$ $(68 \%)$ as of 2007 , Germany is the second largest generic drug market in the world, and the largest generic drug market in Europe, experiencing the largest number of generic and early

\footnotetext{
${ }^{7}$ The generic efficiency rate indicates the fraction of multi-source drug prescriptions dispensed as generic. Own calculations based on Insight Health prescription data.
} 
entries between 2000 and 2007 (EUC, 2009). Hence, it is one of the most important pharmaceutical markets to examine when seeking insights into generic and early entry decisions. The following paragraph outlines the market approval process of generic drugs in Germany, the dynamics of generic competition and the underlying market regulations.

Generic drugs are therapeutically equivalent to off-patent, original drugs, i.e. they contain the same active ingredient, they have identical quality and performance characteristics, the same strength and the same or a similar route of administration. Generic drugs are most frequently marketed as INN-generics, i.e. the international-non-proprietary name (INN) of the active ingredient and a company suffix identify the generic product. The originator's market share typically drops quickly after generic entry. The case of Pfizer's bestseller drug Norvasc (INN: Amlodipine) illustrated in Appendix [A-1] is only one prominent example. As a result of price competition and lower R\&D outlays, generic firms offer substantial price discounts of up to $80 \%$ and more. Instead of safety and efficacy tests generic firms run bioequivalence studies $^{8}$ which are cheaper and faster to conduct (on average four months). Generic entry is usually permitted as soon as the original drug goes off-patent. Originators may apply within six month of the drug's market approval for a supplementary protection certificate which extend the exclusivity period by up to five years if granted by the national patent office. Generic entry may occur prior to patent or SPC expiry. ${ }^{9}$ In the event of early entry, a generic version of the original drug may be marketed either through a generic subsidiary or licensee/supply partner. ${ }^{10}$ Independent generic firms file abridged applications for market approval, referring to the reviews of experts and clinical test results obtained in the course of the original drug's approval process. Current law entitles generic firms to cite such documents without notice or permission of the originator eight years after the original drug's market entry ${ }^{11}$ (data exclusivity period). ${ }^{12}$ If the data exclusivity period elapsed,

\footnotetext{
${ }^{8}$ Generic manufacturers prove in bioequivalence studies that the rate and extent of absorption of the active ingredient is identical to that of the reference drug.

${ }^{9}$ EUC (2008), pp. 11, 246; The Economist, August $6{ }^{\text {th }}$ 2009: "Friends for Life"; "Something Rotten".

${ }^{10}$ Original drug producers appear to decide on early arrangements on a case-by-case basis most often in the year prior to loss of exclusivity to generate substantial profits (EUC, 2009).

${ }^{11}$ Given time and cost-intensive clinical trials and a lengthy approval process, market entry of the original drug typically occurs 10-12 years after patent application.

${ }^{12}$ With the implementation of the Bolar provision in German law, "working under patent" became legal. For applications filed in Germany prior to November 2005 the data exclusivity period amounts to 10 years.
} 
generics may conduct bioequivalence studies while the reference drug is still patent-protected (working under patent). However, generic drugs are not to be marketed (marketing exclusivity period) for 10 years after the original drug's market entry. If the originator obtains market approval for at least one additional indication within eight years after market entry, the marketing exclusivity period is extended for another year $(8+2+1$-Rule). A centralized application procedure has increasingly been used by generic firms since 2000 (EUC, 2008), providing market authorization for the European community at once. Applications are submitted for evaluation to the European Medication Evaluation Agency (EMEA), which gives a recommendation to the European Commission within 270 days unless major objections are identified. The European Commission grants market approval and informs the applicant.

In summary, generic firms decide upon market entry about two years prior to loss of exclusivity. Due to the disclosure ${ }^{13}$ of generic applications until shortly before the grant of market approval, generic firms sink entry costs simultaneously and can only form expectations about competitors' actions. ${ }^{14}$ Figure 1 below outlines the various exclusivity mechanisms. At the discretion of original drug producers early entry may either occur prior to patent (1) or SPC expiry (2). Independent generic firms enter after patent (or SPC) expiry, depending on the duration of bioequivalence studies and timing of generic drugs' market approval.

Figure 1: From Patent Application to Generic Entry

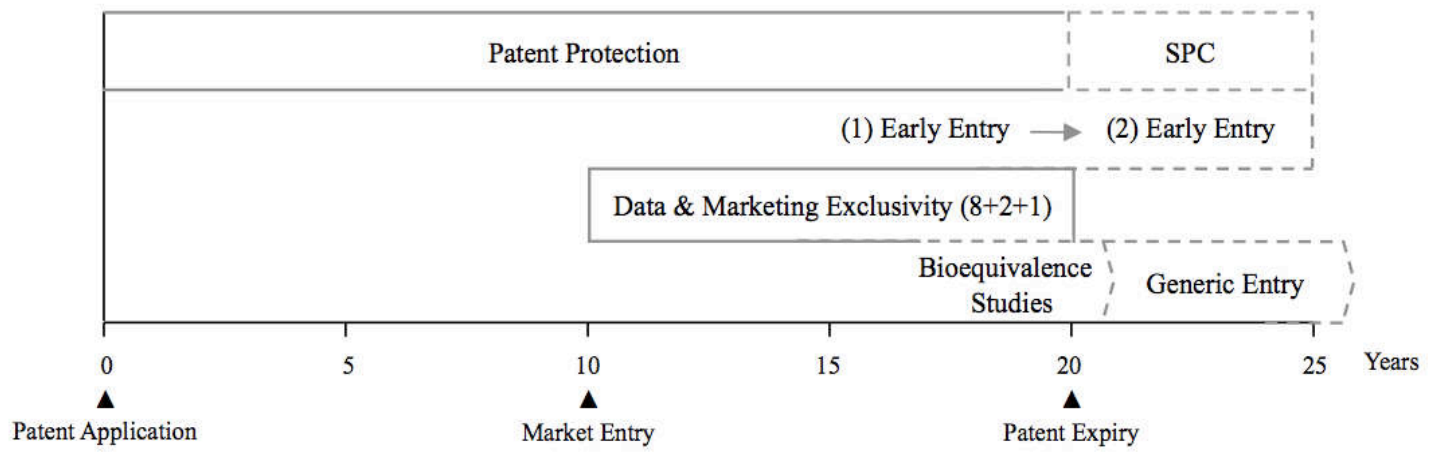

An increase in generic substitution has been achieved through the enforcement of the Drug Expenditure Restriction Act in February 2002, introducing the Aut-idem regulation for

\footnotetext{
${ }^{13}$ See also EUC (2008), p. 15.

${ }^{14}$ Entry costs comprise the costs of conducting bioequivalence studies - $\$ 40.000-150.000$ (WHO, 2005), market approval fees - at the EMEA, an annual fee of $€ 21.700$ in addition to a basic fee of $€ 94.100$ (EUC, 2008) - and legal costs in the event of litigation, settlements etc..
} 
prescription drugs. If doctors do not exclude substitution, a pharmacist generally will have to sell one of the three cheapest generic drugs to the patient. If a more expensive product is sold instead, the pharmacist incurs the difference in price. Since January 2004, dispensing fees on prescription drugs ${ }^{15}$ consist largely of a fixed component. ${ }^{16}$ As a result, incentives to sell high-priced drugs have been reduced. In the same year, reimbursement practices were altered. Patients covered by statutory health insurance have to make a co-payment for each drug they purchase. The co-payment amounts to $10 \%$ of the retail price, the minimum contribution is $€ 5$ and $€ 10$ is the maximum. As most drugs are sold in packages priced below $€ 50$, patients are often inclined not to search for a cheaper drug with the same active ingredient (Accenture, 2005). In addition to the co-payment that patients covered by statutory health insurance must make, they are reimbursed up to a reference price only. As of May 2006, co-payments become obsolete if a drug product is priced $30 \%$ or more below the reference price. ${ }^{17}$ As a result, generic firms often set prices close to, or $30 \%$ below, the reference price ${ }^{18}$. In April 2007 the Statuatory Health Insurance Competition Reinforcement Act was enforced, authorizing rebate contracts. Ever since statutory insurance providers may contract with drug manufacturers that offer the lowest price for a particular drug product. Thereafter, pharmacists are to provide patients with the drug of the manufacturer their insurance provider has contracted with. Except for rebate contracts, previous regulations seem to have provided generally few incentives to switch between identical generic drugs as long as price differences are minor, conferring a sustainable advantage to generic first-movers.

\section{Literature Review}

The distinctive features of competition in off-patent drug markets have attracted the attention of various economists. Previous empirical studies prove pre-entry market size (Morton, 1999; Saha et al., 2006), firm and drug characteristics (Morton, 1999), and the brand-name drug's goodwill stock (Hurwitz and Caves, 1988; Hudson, 2000) to be impor-

\footnotetext{
${ }^{15}$ Around $78 \%$ of pharmaceutical sales are made on prescription drugs (BPI Pharma-Daten 2008).

${ }^{16}$ Pharmacies receive a fixed fee of $€ 8.10$ on each product sold, plus $3 \%$ of the product's purchase price.

${ }^{17}$ To secure fair competition practices, manufacturers are also prohibited from giving discounts in kind to pharmacies since May 2006. Financial rebates are restricted to non-prescription drugs.

${ }^{18}$ AOK Press Release June, 2006 (accessed Dec 11th 2008); see also Accenture (2005).
} 
tant influencing factors of generic entry. A few empirical studies address the issue of early entry - also known as authorized, branded or pseudo-generic entry - gauging its potentially anti-competitive impact on independent generic entry. Early entry is a common phenomenon in both Europe and the USA. Generic first-movers have been shown to enjoy a long-lasting advantage over subsequent generic entrants (Caves et al., 1991; Grabowski and Vernon, 1992; Hollis, 2002). ${ }^{19}$ Not only can the first generic entrant serve the market for a longer period of time - with fewer competitors and higher generic profits after patent expiry - but it can also capture and sustain a substantially larger market share over a period of several years. On these grounds early entry may drastically reduce incentives for generic entry and harm off-patent competition. Prior studies draw different conclusions about the effect of early entry on generic entry decisions. Whereas Hollis (2003) argues that early entry has a deterring effect on generic entry and substantial welfare effects, Reiffen and Ward (2007) and Berndt et al. (2007a) hold a more moderate view on the ultimate impact of early entry.

Hollis (2003) explains that patients' unwillingness to switch between medications, search and "persuasion" costs on parts of doctors, and the administrative costs of pharmacies when stocking several (identical) generic drugs result in switching costs. Switching costs are not easy to overcome as generic drugs are bio-equivalent and generic competitors match prices immediately as soon as one entrant lowers its price. Referring to a related study (Hollis, 2002) establishing evidence on generic first-mover advantages in Canada, he concludes that brand-controlled pseudo-generics substantially lower incentives for generic entry.

Reiffen and Ward (2007) examine the motivation of original drug manufacturers in the USA to introduce authorized generics pre-patent expiry, addressing the issue of entry deterrence. Based on structural estimates from earlier empirical studies (Caves et al., 1991; Reiffen and Ward, 2005), they calculate the effect of authorized generic entry on generic industry profits and the number of generic entrants in equilibrium, which in turn affects generic and brand prices, and eventually original drug producers' profits. Their calculation shows that the anticipation of (exogeneously given) authorized generic entry crowds out between 1.7 to 2.4 generic entrants regardless of drugs' market size. Reiffen and Ward (2007) argue that

\footnotetext{
${ }^{19}$ Berndt et al. (2002) provide similar evidence for Rx-to-OTC switches of antiulcer and heartburn drugs.
} 
original drug producers introduce authorized generics in large drug markets fueled by rentseeking motives, i.e. to capture generic profits without substantially affecting the number of generic entrants or generic prices. In small and medium-sized markets on the contrary, entry deterrence motives play an important role as the impact on generic entry and prices is relatively large. Reiffen and Ward (2007) argue that early entry is least problematic (from the standpoint of social welfare) and also most profitable in high-revenue drug markets.

Recent evidence on the consumer welfare effects of authorized generic entry in the USA has been provided by Berndt et al. (2007a,b). The studies examine the impact of (exogeneously given) authorized generic entry on the filing of Abbreviated New Drug Approvals $(\mathrm{ANDA})^{20}$ with a paragraph IV certification (claim of patent non-infringement or invalidity), i.e. they look at generic entrants' incentives to enter timely and not necessarily at the actual market entry decision. Under the Hatch-Waxman Act of 1984, the first generic firm to file an ANDA with a successful paragraph IV certification may be granted a 180-day exclusivity period where no other generic firm (except for the authorized generic) is entitled to market the same version of the drug. Berndt et al. (2007b) point out that several factors besides authorized generic entry may limit the profitability of the 180-day exclusivity period. ${ }^{21}$ They show that in spite of the increase in authorized generics since 2003, there is little change in the total number of paragraph IV certifications, paragraph IV certifications per drug, and timing of filings relative to approvals of new chemical entities. Based on a review of descriptive statistics, they conclude that the effect of authorized generic entry on independent generic entry and consumer welfare in the U.S. is likely to be small. Berndt et al. (2007a) emphasize also that there is no comprehensive empirical evidence based on recent data that would show early entry to have had a delaying or deterring effect on generic entry.

\section{Data}

Through a matching of national pharmaceutical market and exclusivity data, a unique data set has been created, tracking substances' losses of exclusivity and generic entry between

\footnotetext{
${ }^{20}$ Abbreviated New Drug Approval: application process for generic entrants in the USA, where therapeutic equivalence to the original drug and quality of the manufacturing process has to be proven.

${ }^{21}$ Multiple entrants are awarded 180-day exclusivity given they apply for the same dose at the same day.
} 
2002 and 2007. Insight Health provides pharmaceutical market, patent and SPC data. ${ }^{22}$ The pharmaceutical market data comprise information on $\operatorname{drugs}^{23}$, medical products and manufacturers. Additionally, they provide product-level information on prices, turnover and revenues generated in the German retail segment. Exclusivity data give information about patent holders, originators, the date of patent and SPC application, the date of first market approval. The analysis is limited to human medications containing one active ingredient to ensure a high matching quality of pharmaceutical and exclusivity data. ${ }^{24}$ Moreover, it is confined to data on retail revenues, i.e. wholesale and direct purchase transactions of public pharmacies. I disregard hospitals sales due to data availability constraints. In Europe, the turnover generated with prescription medications is significantly larger in the retail segment. In 2007 the retail turnover was approximately three times as large as the turnover generated in the hospital segment(EUC, 2008). As a result of quantity discounts, prices charged to hospitals are also typically much lower than retail prices. Thus, for the vast majority of drugs in this study (prescription drugs), retail revenues provide a sufficiently reliable measure of markets' attractiveness. Furthermore, I have not been able to obtain data on advertising expenditures. Pharmaceutical firms spend a substantial fraction of profits on advertising ${ }^{25}$, yet these data are private and for researchers almost impossible to acquire. Pre-expiration brand advertising may not be a barrier to generic entry (Morton, 2000) - original drug producers' intensity of advertising decreases drastically as exclusivity expires (Berndt et al., 2003; Janakiraman et al., 2008; EUC, 2009)-, and generic advertising may be rare (Scherer, 2000; Berndt et al., 2003), the lack of advertising data is certainly a limitation of this study.

79 drugs experienced a loss of exclusivity between 2002 and 2007. Four drugs are excluded from the sample given their uncommon routes of administration (lung, eye and sys-

\footnotetext{
${ }^{22}$ Insight Health has obtained exclusivity data from the national patent and trademark office since 2005 . I accessed the PATDPASPC, Esp@cent Patent, Derwent and Open Drug database, Thomson's Current Patent Gazette, the FDA Orangebook, and online patent expiry reports to complement and verify the data.

${ }^{23}$ Strength, drug form and therapeutic field(s) of indication are specified. The drug form classification follows the New Form Code (NFC) Classification established by the European Pharmaceutical Market Research Association (EphMRA), the classification of therapeutic fields in turn rests upon the Anatomical Therapeutic Chemical (ATC) Classification System which was introduced by the WHO in 1976.

${ }^{24}$ The consistency of generic entry and exclusivity data was verified. If generic entry occurred prior to patent or SPC expiry, investigations were carried out to find evidence on early entry or patent invalidity cases that would explain entry prior to the official date of patent or SPC expiry.

${ }^{25}$ Direct advertising of prescription medications to consumers is illegal in the European Union.
} 
temic use $)^{26}$, confining the analysis to 75 markets with a predominantly oral, topical or parenteral drug form use. SPC extensions were granted for 60 drugs. By the end of 2007, 87 generic firms entered in 48 out of the 75 markets $^{27}$, resulting in a total of 724 generic entries. ${ }^{28}$ As generic firms tend to focus on high revenue markets several entry opportunities attract no entry (Morton, 1999; Hollis, 2003). Of the 48 drug markets experiencing generic entry, 16 were affected by early entry - on average four months prior to loss of exclusivity. Licensing/supply agreements were the preferred mode to arrange for early entry. A generic version of the original drug was launched through a generic subsidiary in the case of two drugs only. A total of 26 early entries took place as originators would often cooperate with two generic firms. Table 1 outlines important characteristics of the 75 entry opportunities arising between 2002 and 2007: pre-entry market revenues (in € Mio., evaluated at producer prices, two years prior to loss of exclusivity), the extent of generic entry, the duration of monopoly (number of years from original drug's market approval to loss of exclusivity) and the number of off-patent drugs available (substitutes) treating the same indication(s) ${ }^{29}$.

Table 1: Generic Entry Opportunities (2002-2007)

\begin{tabular}{|c|c|c|c|c|c|c|c|c|}
\hline & \multirow{2}{*}{$\frac{\text { Markets }}{\mathrm{N}}$} & \multicolumn{2}{|c|}{ Pre-Entry Market Size } & \multirow{2}{*}{$\frac{\text { Entries }}{\mathrm{N}}$} & \multicolumn{2}{|c|}{ Monopoly (Yrs.) } & \multicolumn{2}{|c|}{$\underline{\text { Substitutes }}$} \\
\hline & & Mean & Median & & Mean & Median & Mean & Median \\
\hline Generic Entry & 48 & 47.8 & 32.9 & 724 & 12.3 & 12.5 & 50.7 & 43.5 \\
\hline Early Entry & 16 & 55.6 & 39.8 & 301 & 12 & 12.5 & 45.9 & 33.5 \\
\hline No Early Entry & 32 & 43.9 & 25.2 & 423 & 12.5 & 12.5 & 53.1 & 45.5 \\
\hline No Generic Entry & 27 & 0.6 & 0.2 & 0 & 11.7 & 13 & 42.9 & 35 \\
\hline$\overline{\text { Total }}$ & 75 & 32.7 & 14.8 & 724 & 12.1 & 12.5 & 47.9 & 39 \\
\hline
\end{tabular}

Notably, very small markets experience no generic entry. The average pre-entry market size of drug markets experiencing generic entry amounts to of $€ 47.8$ Mio.. Also, early entry appears to be focused on high revenue markets comparing either mean or median pre-entry market sizes of the given markets. Grouping the 25 smallest, the 25 intermediate-sized and 25 largest drug markets with an average pre-entry market size of $€ 2.2$ Mio., $€ 17.6$ Mio. and $€ 78.3$ Mio., I find evidence for a monotonic relationship between generic entry (early entry) and pre-entry market size. Generic entry (early entry) occurs in 4 (1) small-revenue, in 21

\footnotetext{
${ }^{26}$ Only Formoterol attracts generic entry (route of administration: lung).

${ }^{27}$ Other studies report similar rates of generic entry, e.g. Magazzini et al. (2004).

${ }^{28} \mathrm{As}$ one firm typically enters in more than one market, this yields 724 generic entries.

${ }^{29}$ Therapeutic fields are classified by the ATC System at the second level of aggregation (ATC2).
} 
(4) intermediate-sized and in 23 (11) high-revenue markets. Differences in the duration of monopoly are generally minor. Original drug producers exclusively supplied drug markets for approximately 12 years on average. Generic entrants also appear to enter more "crowded" (profitable) therapeutic fields. The number of available, off-patent drugs (substitutes) treating the same indication(s) - a measure of the intensity of off-patent competition prior to generic entry - tends to be larger in the 48 markets experiencing generic entry. Appendix [A-2] illustrates the patterns of losses of exclusivity, generic entry and early entry from 2002 to 2007 and it sketches the highly left-skewed distribution of pre-entry market sizes.

The unit of observation in the analysis is the market entry decision of a generic firm. Observing firms that decided to enter, one remains agnostic about those firms which refrained from entry. For an examination of generic entry decisions, negative entry decisions (zeroentries) need to be accounted for, however. As in Morton (1999), sets of potential entrants are constructed for each substance to identify generic firms that could have entered but decided not to do so. ${ }^{30}$ The pharmaceutical data set lists around 985 firms that supplied the German pharmaceutical market between 1999 and 2007. By restricting the set of potential entrants to manufacturing firms (no re-import ${ }^{31}$ ) with at least half of the retail form portfolio being classified as "generic", 395 firms remain. By limiting the set of potential entrants further to those firms with a portfolio of at least 50 retail forms the number of firms is reduced to 101. These 101 firms manufactured $94.4 \%$ of all generic retail forms available on the German market between 1999 and 2007. The first set of potential entrants is defined for each drug market by including only those firms that are in business as exclusivity expires (Data Set 1). The criteria might seem arbitrary at first, yet they turn out to predict generic entry decisions very well. 672 out of 724 generic entries are correctly identified, i.e. a fraction of $92.8 \%$ of all generic entries between 2002 and 2007. The criteria should be similarly apt to identify potential entry candidates which eventually refrained from entry. A further restriction of entry candidates may be warranted as not all of those firms were similarly likely to have decided upon each of the 75 entry opportunities. Morton (1999) finds that generic firms

\footnotetext{
${ }^{30}$ Kyle (2007) determines market entry opportunities in a similar context. See also Kyle (2006).

${ }^{31}$ As of 2007 reimport firms have supplied only a minor fraction of $3.9 \%$ of all generic retail forms.
} 
therapeutic and drug form experiences influence generic entry decisions positively. Two further sets of potential entrants are created for each and every drug market to account for potential entrants' experiences. The second set of potential entrants limits entry candidates in the first set of potential entrants to those firms which prove to be experienced in the relevant fields of indication as exclusivity expires, having marketed a positive number of retail forms in given therapeutic fields (Data Set 2). The third set of potential entrants lastly restricts the second set of entry candidates to those firms which additionally have expertise in manufacturing the relevant drug form(s) as exclusivity expires, having launched a positive number of particular drug forms (Data Set 3). Table 2 below summarizes the sets of criteria employed, providing an overview of the three data sets which were generated.

Table 2: Outline Data Set Construction

\begin{tabular}{|c|c|c|c|}
\hline & Data Set 1 & Data Set 2 & Data Set 3 \\
\hline Definition & 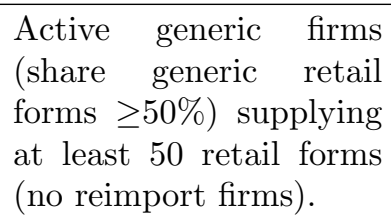 & $\begin{array}{l}\text { Firms in Data Set } 1 \\
\text { which are active in the } \\
\text { relevant field(s) of indi- } \\
\text { cation (ATC2). }\end{array}$ & $\begin{array}{l}\text { Firms in Data Set } 2 \\
\text { with drug form experi- } \\
\text { ence (NFC1). }\end{array}$ \\
\hline \multicolumn{4}{|c|}{ Potential Entrants } \\
\hline Total & 127 & 126 & 126 \\
\hline Mean & 100.2 & 37.4 & 33.7 \\
\hline Median & 101 & 38 & 34 \\
\hline \multicolumn{4}{|l|}{ Zero-Entries } \\
\hline Total & 6793 & 2080 & 1807 \\
\hline 48 & 4081 & 1251 & 1058 \\
\hline 27 & 2712 & 829 & 749 \\
\hline Mean & 90.6 & 27.7 & 24.1 \\
\hline 48 & 85.0 & 26.1 & 22.0 \\
\hline 27 & 100.4 & 30.7 & 27.7 \\
\hline Median & 93 & 23 & 21 \\
\hline 48 & 85.5 & 22 & 19 \\
\hline 27 & 101 & 31 & 30 \\
\hline
\end{tabular}

\begin{tabular}{|c|c|c|c|}
\hline \hline Generic Entries & \multicolumn{3}{|c|}{} \\
\hline Total & & 724 & \\
Mean & & 15.1 & \\
Median & & 14 & 2531 \\
\hline \hline Sample Size (N) & 7517 & 2804 & \\
\hline
\end{tabular}

Notes: Statistics for generic entries refer to the 48 drug markets experiencing generic entry by 2007, whereas statistics for potential entrants and statistics for zero-entries are presented for all 75 drug markets in the sample. Latter statistics are additionaly disaggregated by drug markets with (48) and without (27) generic entry. 
With an increasing limitation of the total number of potential entrants from data set 1 to data set 3 , the average and median number of potential entrants declines notably. ${ }^{32}$ The same applies to the number of zero-entries and sample sizes. There are on average about 100, 37 and 34 potential entrants for one drug market. Given that there are around 50-60 generic firms in Germany, and given that innovative pharmaceutical firms would supply generic drugs in various instances (acis Arzneimittel GmbH, 2007), too, these numbers appear to be reasonable. Between 2002 and 2007, 48 drug markets experienced generic entry. A total of 724 generic entries occurred in the given time period. Approximately 15 generic firms entered into one drug market. Appendix [B] provides an overview of the distribution of generic entries and negative entry decisions (zero-entries) over the 75 drug markets. Depending on the established criteria for sets of potential entrants, a fraction of $9.6 \%, 26 \%$ and $29 \%$ of the various entry opportunities are realized. Morton (1999) examines 123 firms and 363 drug markets (drug and drug form combinations) and uses a similar methodology, yet somewhat different criteria to identify potential entrants. Having created substantially more entry opportunities in each of the three data sets $\left(N_{1}=42059, N_{2}=33979, N_{3}=23811\right)$, Morton (1999) finds that only a fraction of $2 \%, 3.5 \%$ and $7 \%$ of observations experience generic entry. As such, my criteria are not necessarily less restrictive than the criteria employed in the previous study. ${ }^{33}$ In general, the more restrictive criteria I employ, the smaller become not only the sets of potential entrants assigned to drug markets but also the fractions of correctly predicted generic entry decisions. Some generic firms enter unknown therapeutic fields and a few firms also launch new drug forms. Using the second (third) set of criteria to identify potential entrants, $78.7 \%$ (76.5\%) of generic entry decisions are correctly predicted. Any of the criteria employed to identify potential entrants in the specific drug markets seem to predict generic entry decisions sufficiently well. Therefore, any of the criteria should be similarily suitable to identify generic firms which decided not to enter. Using all of the three data sets in the empirical analysis allows me to verify the robustness of results.

\footnotetext{
${ }^{32}$ Whenever firms which are not tracked in the sets of potential entrants enter markets, the total number of potential entrants increases from 101 to 127 , and to 126 respectively.

${ }^{33}$ Examining 1444 unique molecules produced by 278 firms in 134 therapeutic classifications over the time period 1980-1999 in 28 European countries, Kyle (2007) identifies 299567 entry opportunities (drug-countryclass-year observations), out of which 7,630 had a product launch $(2.5 \%)$.
} 


\section{Empirical Implementation}

Using the three cross-sectional micro data sets, I examine the impact of early entry on independent generic entry decisions. Generic first-movers have been shown to enjoy a long-lasting competitive advantage over subsequent generic entrants (Caves et al., 1991; Grabowski and Vernon, 1992; Hollis, 2002) as a result of doctors', patients' and pharmacists' switching costs (see Section $2 \& 3$ ). Along those lines, early entry is likely to diminish the expected profitability of subsequent generic entry (EUC, 2009). As generic manufacturers are uncertain about competitors' entry decisions until shortly before competitors obtain market approval, generic firms can only form expectations about the event of early entry when deciding upon the conduct of bio-equivalence studies and market entry. The underlying assumption made in all related studies is that generic firms are apt to forsee the occurence of early entry (Hollis, 2003; Reiffen and Ward, 2005; Berndt et al., 2007a,b). Given its frequency - firms presumably learning from past experiences - this assumption appears to be reasonable. The hypothesis which the empirical model fundamentally relies on, is specified below. I make no further assumptions about the size of the early entry effect.

Hypothesis: Early entry prior to loss of exclusivity has a significantly negative effect on independent generic entry decisions (deterrence effect).

Both generic entry and early entry are dichotomous variables. One observes market entry but not the profits generic firms or early entrants (original drug producers) expected to reap upon entry (latent variable), which in turn motivated firms' entry decision. For the majority of generic firms early entry is practically "exogenously" given, i.e. they have no means to directly influence original drug producers' decisions. Yet, there is no reason to believe that early entry is truly exogenous. The set of drug markets in which early entry occurs is not a random selection of markets (Hollis and Liang, 2006; FTC, 2009). Unobserved factors determine expected market profits, and thus both the likelihood of generic and early entry. For instance, therapeutic innovations change the future competitive landscape and may let entry into a certain market appear less attractive than observed market characteristics suggest. On the contrary, long-term clinical studies may reveal that a substance is very

effective in a specific therapeutic field, and entry becomes more attractive. Demographic 
trend projections possibly affect expected profits as well. If generic and early entry occur in selective drug markets which are more attractive than given market characteristics suggest - the most likely scenario -, there will be a spurious correlation between early entry and generic entry decisions. The selection effect may understate the effect of early entry, basically counterbalancing the presumably negative effect of early entry. In other words, the early entry dummy may to some extent pick up drug markets' (unobserved) attractiveness.

Ignoring endogeneity issues, I estimate a univariate probit model in the first step to obtain a basic insight into the impact of early entry $\left(e e_{i}\right)$ on the generic entry decision of firm $j$ in market $i\left(g_{i j}\right)$. As previous empirical studies on generic entry (Hurwitz and Caves, 1988; Morton, 1999; Hudson, 2000; Saha et al., 2006; Moreno-Torres et al., 2009), I control for pre-entry market size, the duration of monopoly, the number of off-patent substitute active ingredients, therapeutic field, drug form and year fixed effects $(\mathbf{X})$. I also account for potential entrants' capabilities, i.e. their therapeutic and drug form experiences $\left(\mathbf{C}_{\mathbf{i j}}\right)$. Firms' experiences influence generic entry decisions strongly (Morton, 1999; Kyle, 2006). In all regressions standard errors are robust to heteroscedasticity and clustered - firms' entry decisions are arguably not independent. The univariate probit model is specified below.

$$
g_{i j}=1\left[g_{i j}^{*}>0\right] \text { where } g_{i j}^{*}=\mathbf{X} \boldsymbol{\beta}+\mathbf{C}_{\mathbf{i j}} \boldsymbol{\alpha}+\delta e e_{i}+\epsilon_{i j}
$$

In order to allow for a correlation $(\rho)$ between generic entry and early entry decisions over the error terms and to provide evidence for selection, I estimate a recursive bivariate probit model in the second step. The bivariate probit model is a natural extension to the univariate probit model. The error terms $\epsilon_{i j}$ and $\mu_{i}$ are assumed to be distributed bivariate normal, with $E\left(\epsilon_{i j}\right)=E\left(\mu_{i}\right)=0, \operatorname{Var}\left(\epsilon_{i j}\right)=\operatorname{Var}\left(\mu_{i}\right)=1$ and $\operatorname{Cov}\left(\epsilon_{i j}, \mu_{i}\right)=\rho$. Evans and Schwab (1995) adopt this empirical approach in a seminal paper. Various studies in health economics trying to gauge the impact of a binary endogenous treatment on a binary outcome rely on the recursive bivariate probit model (Goldman et al., 2001; Jones et al., 2006). Bhattacharya et al. (2006) conduct a Monte Carlo exercise to evaluate the consistency of multivariate probit, two-stage probit and two-stage least squares estimators when examining the impact of a binary treatment on a binary outcome in a non-randomized setting. 
Bhattacharya et al. (2006) point out that the results argue in favor the multivariate probit, especially when the average probability of the dependent variable is close to 0 or 1 , or when the data generating process is not normal. The identification strategy in the bivariate probit model relies on the assumption of normality and the fact that I am modeling sequential entry decisions. Exclusion restrictions are not necessarily required to achieve identification in recursive bivariate probit models (Wilde, 2000; Greene, 2008) ${ }^{34}$. I do impose one exclusion restriction, however, to improve identification. As early entry decisions are arguably motivated by original drug producers' financial distress, I add a count of each original drug producers' further losses of exclusivity in the time period 2002 to 2007 as instrumental variable to the early entry equation (I). Past losses of exclusivity are included. Original drug producer's financial distress is expected to have a positive effect on the likelihood of early entry. Original drug producers who do not experience many patent expiries in the given time period are ceteris paribus financially better off and depend less on current income streams and their preservation. Out of the 19 originators in the sample, 11 originators conclude early entry agreements facing on average 3.4 further losses of exclusivity, whereas the remaining 8 originators experience on average only 0.5 further losses of exclusivity between 2002 and 2007. The number of original drug producers' further losses of exclusivity is exogenously given, forming only a small subset ${ }^{35}$ of all entry opportunities in the given time period. The high frequency of early entry suggests that original drug producers primarily make use of early entry arrangements to mitigate the loss of monopoly profits. Original drug producers' advertising efforts in a given market are known to decline around the time of patent expiry and to drastically decline thereafter (Berndt et al., 2003; Janakiraman et al., 2008; EUC, 2009), suggesting that advertising is not an alternative channel through which original drug producers' financial distress would impact independent generic entry decisions.

If, after controlling for other observed drug market and firm characteristics, Financial Distress is correlated with generic firms' unobserved propensity to enter into a given market, it will not provide a valid exclusion restriction. One straightforward way to address this

\footnotetext{
${ }^{34}$ Review also online material provided by William Greene (accessed December 2009): pages.stern.nyu.edu/ wgreene/DiscreteChoice/Lectures/Part5-Bivariate\&MultivariateProbit.ppt

${ }^{35}$ Original drug producers face on average 2.2 further losses of exclusivity between 2002 to 2007 .
} 
issue, yet not a formal test, is to include the instrumental variable in the single-equation probits. Single-equation models are misspecified if there is selection, but they still offer a a clear sense of the patterns in the data (Evans and Schwab, 1995). Besides this tentative empirical evidence for the suitability of the instrument, I conduct a likelihood-ratio test of the restricted versus unrestricted recursive bivariate probit model showing that the instrument improves identification and the model's goodness of fit. The recursive bivariate probit model's specification is given below. It is identical to the univariate probit model except for the second equation - the early entry decision $e e_{i}$ - which is now additionally to be estimated. Due to lack of variation in the data, drug form effects are not accounted for in the early entry equation. Early entry occurs in drug markets with oral drug form use only.

$$
\begin{aligned}
& g_{i j}=1\left[g_{i j}^{*}>0\right] \quad \text { where } g_{i j}^{*}=\mathbf{X}_{\mathbf{1}} \boldsymbol{\beta}_{\mathbf{1}}+\mathbf{C}_{\mathbf{i j}} \boldsymbol{\alpha}+\delta e e_{i}+\epsilon_{i j} \\
& e e_{i}=1\left[e e_{i}^{*}>0\right] \text { where } e e_{i}^{*}=\mathbf{X}_{\mathbf{2}} \boldsymbol{\beta}_{\mathbf{2}}+\mathbf{I} \boldsymbol{\tau}+\mu_{i}
\end{aligned}
$$

The dependent variable of particular interest in all regressions is Generic Entry, denoting the market entry decision of an independent generic firm. Generic Entry is coded as 0-1 dummy and it takes on the value one if an independent generic firm decides to enter a specific drug market post loss of exclusivity. The Early Entry dummy regressor - introduced to generic entry equations to examine the effect of early entry on generic entry decisions similarly takes on the value one if a generic version of the original drug is launched in a specific drug market prior to loss of exclusivity. Pre-Entry Market Size is a fundamental control variable in generic (early) entry equations (Berndt et al., 2007a; Fisher Ellison and Ellison, 2007; Reiffen and Ward, 2007). Pre-Entry Market Size denotes the annual revenues in logarithms in a given market two calendar years prior to loss of exclusivity (evaluated at producer prices, in $€ \mathrm{Mio})$. I use a lagged version of the variable to avoid endogeneity issues. Monopoly Duration and Substitutes are two further, important control variables in generic (early) entry equations. Monopoly Duration measures the number of years from the original drug's first market approval to loss of exclusivity. Previous studies have shown that the effective duration of monopoly has a negative effect on generic entry, mainly arguing that original drug producers' goodwill stocks are larger (Hurwitz and Caves, 1988; Hudson, 2000). Substitutes proxies the intensity of off-patent competition in therapeutic fields, indicating 
the number of off-patent substitute active ingredients available in a particular therapeutic field. Whenever off-patent drugs fall into the same ATC2 class as the drug in question, they are counted as substitutes ${ }^{36}$, a common approach in the literature (Kyle, 2007). The intensity of off-patent competition is assumed to affect generic (early) entry decisions negatively (Moreno-Torres et al., 2009). The variables Field Experience and Form Experience are introduced in generic entry equations to account for potential entrants' capability to enter specific markets. Field Experience serves a proxy for potential entrants' therapeutic experience, denoting the number of retail forms the generic firm has launched in the relevant therapeutic fields prior to loss of exclusivity. Similarly, Form Experience is a count of the number of retail forms the generic firm has marketed of a specific drug form, proxying the firm's drug form experience. A summary of all definitions is provided in Table 3 below.

Table 3: Definition of Variables

\begin{tabular}{|c|c|}
\hline Variable Name & Definition \\
\hline Generic Entry & $\begin{array}{l}\text { 0-1 dummy variable, }=1 \text { if independent generic firms decided to enter } \\
\text { drug market post loss of exclusivity (patent or SPC expiry). }\end{array}$ \\
\hline Early Entry & $0-1$ dummy variable,$=1$ if early entry occurs prior to loss of exclusivity. \\
\hline Pre-Entry Market Size & $\begin{array}{l}\text { Annual drug market revenues in logarithms two calendar years prior to } \\
\text { loss of exclusivity, in } € \text { Mio., evaluated at producer prices. }\end{array}$ \\
\hline Monopoly Duration & Number of years from dugs' market approval to loss of exclusivity. \\
\hline Substitutes & $\begin{array}{l}\text { Count of off-patent substitute active ingredients, listed in the same ther- } \\
\text { apeutic field(s) (ATC2 classes) by the time exclusivity expires. }\end{array}$ \\
\hline Field Experience & $\begin{array}{l}\text { Count of potential entrants' retail form launches prior to loss of exclu- } \\
\text { sivity, in therapeutic field(s) (ATC2 Classes) the drug is applicable in. }\end{array}$ \\
\hline Form Experience & $\begin{array}{l}\text { Count of potential entrants' retail form launches prior to loss of exclusiv- } \\
\text { ity, using the particular drug's routes of administration (NFC2 Classes). }\end{array}$ \\
\hline Financial Distress & $\begin{array}{l}\text { Count of further losses of exclusivity which original drug producers' ex- } \\
\text { perience between } 2002 \text { and } 2007 \text {. }\end{array}$ \\
\hline Therapeutic Field & $\begin{array}{l}0-1 \text { dummy variable, }=1 \text { if drug is applicable in therapeutic field prior to } \\
\text { loss of exclusivity (ATC1 Classes: } 13 \text { ATC } 1 \text { dummies). }\end{array}$ \\
\hline Drug Form & $\begin{array}{l}0-1 \text { dummy variable }=1 \text { if drug has been primarily administered orally, } \\
\text { parenterally or topically prior to loss of exclusivity. }\end{array}$ \\
\hline Year Expiry & $0-1$ dummy variable,$=1$ if loss of exclusivity occurs in $2002, \cdots, 2007$. \\
\hline
\end{tabular}

Remember that the variable Financial Distress is introduced in early entry equations only, providing an exclusion restriction and facilitating identification in recursive bivariate probit regressions. Financial Distress indicates the number of further losses of exclusivity original drug producers' have to face in the time period 2002 to 2007. The more financial losses

\footnotetext{
${ }^{36}$ Of course, substances in the same ATC2 class are not necessarily perfect substitutes. Nevertheless, one obtains a first insight into the degree of off-patent competition in a certain therapeutic field; see Kyle (2007).
} 
original drug producers experience, the larger is presumably the likelihood of early entry. Therapeutic field, (drug form) $)^{37}$ and year fixed effects are accounted for by introducing sets of dummy variables to generic entry and early entry equations. Other variables measuring, for instance, substances' therapeutic applicability, or the number of losses of exclusivity (entry opportunities) in a given year, proved insignificant. Hence, only a parsimonious set of variables is presented. Summary statistics for data set 3 are presented in Table 4 below. Appendices [C1] and [C2] provide summary statistics for Data Sets 1 and 2.

Table 4: Summary Statistics Data Set 3

\begin{tabular}{|l|cccccc|}
\hline Variable Name & Mean & Median & Min. & Max. & Sd. & N \\
\hline \hline Generic Entry & 0.29 & 0 & 0 & 1 & - & 2531 \\
Early Entry & 0.24 & 0 & 0 & 1 & - & 2531 \\
Pre-Entry Market Size (€Mio.) & 37.5 & 20.1 & 0 & 187 & 44.5 & 2531 \\
Pre-Entry Market Size (log) & 16.08 & 16.82 & 0 & 19.05 & 3.20 & 2531 \\
Monopoly Duration & 11.86 & 12.5 & 5 & 20 & 3.0 & 2531 \\
Substitutes & 53.97 & 44 & 8 & 204 & 36.28 & 2531 \\
Field Experience & 26.38 & 12 & 0 & 374 & 37.43 & 2531 \\
Form Experience & 178.8 & 85 & 0 & 1679 & 224.97 & 2531 \\
Financial Distress & 2.92 & 2 & 0 & 6 & 2.47 & 2531 \\
\hline
\end{tabular}

Given the different composition of the three data sets (Section 4), the distribution of variables differs. For instance, with the number of zero-entries decreasing from Data Set 1 to Data Set 3, the fraction of positive generic decisions increases. So does the fraction of generic entry decisions affected by early entry. The fraction of positive generic entry decisions amounts to roundabout $29 \%$ in Data Set 3. About $24 \%$ of generic entry decisions are affected by early entry. The average generic entry decision is made for a drug market with pre-entry revenues of $€ 37.5$ Mio., where original drug producers enjoyed a duration of monopoly of about 11.9 years $^{38}$, and faced roughly three further losses of exclusivity between 2002 and 2007. Potential entrants decide upon drug launches in therapeutic fields with on average 54 off-patent, available substitutes prior to drugs' loss of exclusivity. Before entry opportunity arose, potential entrants marketed on average 26 retail forms in the relevant therapeutic fields, and 179 retail forms using the specific drug's routes of administration.

\footnotetext{
${ }^{37}$ As early entry occurs in drug markets with oral drug form use only, drug form fixed effects cannot be controlled for in early entry equations.

${ }^{38}$ Grabowski and Kyle (2007) find similar average market exclusivity periods for the same time interval.
} 


\section{Results}

In order to provide basic insights into the impact of early entry on independent generic entry decision, a univariate probit model, ignoring any endogeneity issues, is estimated at first. An overview of the estimates obtained from each of the three data sets is given in Table 5 below. Coefficients look remarkably similar, even though the composition of the data sets varies. Univariate probit estimates indicate that early entry has an adverse effect on generic entry decisions, the size and precision of the estimate notably decreasing from Data Set 1 to Data Set 3. The early effect obtained for Data Set 3 is not significant anymore.

Table 5: Univariate Probit - Coefficients

\begin{tabular}{|c|c|c|c|}
\hline & $\begin{array}{c}\text { Data Set } 1(\mathrm{~N}=7517) \\
\text { Generic Entry }\end{array}$ & $\begin{array}{c}\text { Data Set } 2(\mathrm{~N}=2804) \\
\text { Generic Entry }\end{array}$ & $\begin{array}{c}\text { Data Set } 3(\mathrm{~N}=2531) \\
\text { Generic Entry }\end{array}$ \\
\hline Early Entry $(0 / 1)$ & $\begin{array}{c}-0.2159^{* * *} \\
(0.055)\end{array}$ & $\begin{array}{c}-0.1554^{*} \\
(0.074)\end{array}$ & $\begin{array}{l}-0.1392 \\
(0.076)\end{array}$ \\
\hline $\begin{array}{l}\text { Pre-Entry } \\
\text { Market Size }(\log )\end{array}$ & $\begin{array}{c}0.5796^{* * *} \\
(0.045)\end{array}$ & $\begin{array}{c}0.7311^{* * *} \\
(0.049)\end{array}$ & $\begin{array}{c}0.7740^{* * *} \\
(0.049)\end{array}$ \\
\hline Monopoly Duration & $\begin{array}{c}0.1215^{* * *} \\
(0.013)\end{array}$ & $\begin{array}{c}0.1441^{* * *} \\
(0.016)\end{array}$ & $\begin{array}{c}0.1484^{* * *} \\
(0.017)\end{array}$ \\
\hline Substitutes & $\begin{array}{l}-0.0018 \\
(0.001)\end{array}$ & $\begin{array}{c}-0.0081^{* * *} \\
(0.001)\end{array}$ & $\begin{array}{c}-0.0079^{* * *} \\
(0.001)\end{array}$ \\
\hline Field Experience & $\begin{array}{c}0.0139^{* * *} \\
(0.002)\end{array}$ & $\begin{array}{c}0.0078^{* * *} \\
(0.002)\end{array}$ & $\begin{array}{c}0.0075^{* * *} \\
(0.002)\end{array}$ \\
\hline Form Experience & $\begin{array}{l}0.0030^{* * *} \\
(3.1 \mathrm{e}-04)\end{array}$ & $\begin{array}{l}0.0022^{* * *} \\
(3.4 \mathrm{e}-04)\end{array}$ & $\begin{array}{l}0.0021^{* * *} \\
(3.4 \mathrm{e}-04)\end{array}$ \\
\hline Therap. Field $(0 / 1)$ & yes & yes & yes \\
\hline Drug Form $(0 / 1)$ & yes & yes & yes \\
\hline Year Expiry $(0 / 1)$ & yes & yes & yes \\
\hline Const. & $-11.4171^{* * *}$ & $-13.1081^{* * *}$ & $-13.6092^{* * *}$ \\
\hline $\begin{array}{l}\text { Prob > chi2 }(23) \\
\text { Log-Likelihood }\end{array}$ & $\begin{array}{c}<0.001 \\
-1403.64\end{array}$ & $\begin{array}{r}<0.001 \\
-978.15\end{array}$ & $\begin{array}{c}<0.001 \\
-914.91\end{array}$ \\
\hline
\end{tabular}

Notes: An observation in the regression is the decision of a generic firm to enter a drug market post loss of exclusivity (generic entry). Heteroskedasticity-robust and clustered standard errors in parentheses. Oral drugs in parasitology and sense organs with loss of exclusivity in 2002 form the reference group in generic entry equations.

Generic entry decisions are significantly and positively influenced by pre-entry market sizes in turn, regardless which regression estimates one refers to. Monopoly Duration also has a significantly positive impact on independent generic entry decisions, which is a rather striking result. Previous studies show that the effective duration of monopoly has a nega- 
tive effect on generic entry, arguing that original drug producers' goodwill stocks are larger (Hurwitz and Caves, 1988; Hudson, 2000). One explanation for the different result is that the two earlier studies rely on data from the 80s and 90s. Given the recent institutional and legal changes in Germany (e.g. the enforcement of the Aut-idem regulation in 2002), the U.S. and many other pharmaceutical markets to foster generic substitution, the length of the exclusivity period may not necessarily serve as a good proxy for the accumulated goodwill of pioneers anymore. ${ }^{39}$ The various initiatives taken to promote generic substitution likely neutralized pioneers' reputation advantage, and as a result generic firms will benefit first and foremost if medications are well-established. The number of available off-patent substitutes a measure of the intensity of off-patent competition - appears to affect independent generic entry decisions negatively. The effect of Substitutes is significant except for the estimate obtained for Data Set 1. Both therapeutic and drug form experience encourages generic entry. The effects are generally positive and significant. Therapeutic field, drug form and year fixed effects are significant in any of the univariate probit regressions.

Remember that if generic entry and early entry occur in selective drug markets which are more attractive than given market characteristics suggest, there will be a spurious correlation between early entry and generic entry decisions, i.e. univariate probit estimates will be inconsistent. In order to allow for a correlation between generic entry and early entry decisions through unobservables, I estimate a recursive bivariate probit model in the second step. The variable Financial Distress is added as instrument to the early entry equation to facilitate identification. Univariate probit estimates provide tentative empirical evidence that Financial Distress provides a valid exclusion restriction. Once added to the single-equation probit regressions, it turns out not significantly impact generic entry decisions. Appendix [D] presents the estimates. Note also, that the exclusion restriction is not required to achieve identification, yet it improves identification notably. Appendix [E-1] provides the bivariate probit estimates, relying on a functional form identification strategy. The recursive bivariate probit estimates are generally robust to the identification strategy pursued, i.e. results do not critically hinge on the exclusion restriction. Likelihood-ratio tests of the restricted

\footnotetext{
${ }^{39}$ Results are robust to the exclusion of Monopoly Duration from generic entry and early entry equations.
} 
versus unrestricted bivariate probit model suggest, however, that the inclusion of the instrument improves the identification and the model's overall goodness of fit. The results of the Likelihood-ratio tests are reported in Appendix [E-2]. As Financial Distress appears to be a suitable instrument, improving the bivariate probit model's identification, I confine the following interpretation of results to the estimates of the unrestricted recursive bivariate probit model. Table 6 provides the according estimates. The (residual) correlation between generic and early entry decisions, denoted by the correlation coefficient $\rho$, is large and significantly positive. Wald-Tests show that the null hypothesis of $\rho=0$ can be rejected.

Table 6: Recursive Bivariate Probit - Coefficients

\begin{tabular}{|c|c|c|c|c|c|c|}
\hline & \multicolumn{2}{|c|}{ Data Set $1(N=7517)$} & \multicolumn{2}{|c|}{ Data Set $2(N=2804)$} & \multicolumn{2}{|c|}{ Data Set $3(\mathrm{~N}=2531)$} \\
\hline & $\begin{array}{l}\text { Generic } \\
\text { Entry }\end{array}$ & $\begin{array}{l}\text { Early } \\
\text { Entry }\end{array}$ & $\begin{array}{c}\text { Generic } \\
\text { Entry }\end{array}$ & $\begin{array}{l}\text { Early } \\
\text { Entry }\end{array}$ & $\begin{array}{c}\text { Generic } \\
\text { Entry }\end{array}$ & $\begin{array}{l}\text { Early } \\
\text { Entry }\end{array}$ \\
\hline Early Entry $(0 / 1)$ & $\begin{array}{c}-1.6490^{* * *} \\
(0.079)\end{array}$ & & $\begin{array}{c}-1.5845^{* * *} \\
(0.057)\end{array}$ & & $\begin{array}{c}-1.5531^{* * *} \\
(0.060)\end{array}$ & \\
\hline $\begin{array}{l}\text { Pre-Entry } \\
\text { Market Size (log) }\end{array}$ & $\begin{array}{c}0.8145^{* * *} \\
(0.035)\end{array}$ & $\begin{array}{c}0.7986^{* * *} \\
(0.010)\end{array}$ & $\begin{array}{c}0.9221^{* * *} \\
(0.043)\end{array}$ & $\begin{array}{c}0.8822^{* * *} \\
(0.038)\end{array}$ & $\begin{array}{c}0.9841^{* * *} \\
(0.043)\end{array}$ & $\begin{array}{c}0.9386^{* * *} \\
(0.043)\end{array}$ \\
\hline Monopoly Duration & $\begin{array}{c}0.1092^{* * *} \\
(0.009)\end{array}$ & $\begin{array}{c}0.0511^{* * *} \\
(0.001)\end{array}$ & $\begin{array}{c}0.1459^{* * *} \\
(0.012)\end{array}$ & $\begin{array}{c}0.0878^{* * *} \\
(0.011)\end{array}$ & $\begin{array}{c}0.1583^{* * *} \\
\quad(0.013)\end{array}$ & $\begin{array}{c}0.1155^{* * *} \\
(0.012)\end{array}$ \\
\hline Substitutes & $\begin{array}{c}-0.0035^{* * *} \\
(8.7 \mathrm{e}-04)\end{array}$ & $\begin{array}{c}-0.0011^{* * *} \\
(1.6 \mathrm{e}-04)\end{array}$ & $\begin{array}{c}-0.0060^{* * *} \\
(0.001)\end{array}$ & $\begin{array}{c}0.0017^{*} \\
(0.001)\end{array}$ & $\begin{array}{c}-0.0069^{* * *} \\
(0.001)\end{array}$ & $\begin{array}{l}0.0004 \\
(0.001)\end{array}$ \\
\hline Field Experience & $\begin{array}{c}0.0123^{* * *} \\
(0.002)\end{array}$ & - & $\begin{array}{c}0.0068^{* * *} \\
(0.001)\end{array}$ & - & $\begin{array}{c}0.0067^{* * *} \\
(0.001)\end{array}$ & - \\
\hline Form Experience & $\begin{array}{c}0.0022^{* * *} \\
(2.7 \mathrm{e}-04)\end{array}$ & - & $\begin{array}{c}0.0017^{* * *} \\
(2.5 \mathrm{e}-04)\end{array}$ & - & $\begin{array}{c}0.0016^{* * *} \\
(2.6 \mathrm{e}-04)\end{array}$ & - \\
\hline Financial Distress & - & $\begin{array}{c}0.0676^{* * *} \\
(0.004)\end{array}$ & - & $\begin{array}{c}0.0691^{* * *} \\
(0.011)\end{array}$ & - & $\begin{array}{c}0.0689^{* * *} \\
(0.010)\end{array}$ \\
\hline Therap. Field $(0 / 1)$ & yes & yes & yes & yes & yes & yes \\
\hline Drug Form $(0 / 1)$ & yes & no & yes & no & yes & no \\
\hline Year Expiry $(0 / 1)$ & yes & yes & yes & yes & yes & yes \\
\hline Const. & $-15.0238^{* * *}$ & $-15.0655^{* * *}$ & $-16.4721^{* * *}$ & $-17.0777^{* * *}$ & $-17.4244^{* * *}$ & $-18.1747^{* * *}$ \\
\hline Prob $>\operatorname{chi2}(36)$ & & 001 & $<0$ & & & \\
\hline Log-Likelihood & -38 & 0.52 & -190 & 3.42 & -17 & 5.53 \\
\hline$\rho$ & 0.89 & $6^{* * *}$ & $0.94^{\top}$ & $8 * * *$ & 0.94 & $7 * * *$ \\
\hline Wald Test: chi2(1) & & & 60 & & & \\
\hline Prob $>\operatorname{chi} 2(1)$ & & & & & & \\
\hline
\end{tabular}

Notes: In columns (1), (3) and (5) an observation in the regression is the decision of a generic firm to enter a drug market post loss of exclusivity (generic entry). In columns (2), (4) and (6) the occurrence of early entry prior to loss of exclusivity denotes the dependent variable. Heteroskedasticity-robust and clustered standard errors in parentheses. Oral drugs in parasitology and sense organs with loss of exclusivity in 2002 form the reference group in the generic entry equation. The Wald Test is conducted for the null hypothesis of $\rho=0$, i.e. absence of correlation in the model. 
The finding is robust to the various criteria established for identifying potential entrants. Unobserved factors (favorable market characteristics) appear to stimulate both independent generic and early entry decisions, suggesting that there is a selection effect, or in other words, that early entry is endogenous. Univariate probit estimates turn out to be inconsistent. The coefficient of early entry is significantly negative in any of the bivariate probit regressions. Unless selection is accounted for, the early entry dummy apparently picks up drug markets' (unobserved) attractiveness, counterbalancing and weakening its negative effect on independent generic entry. The coefficient of Financial Distress generally has the expected sign, the effect turning out to be highly significant. The more financial losses original drug producers experience between 2002 and 2007, the larger is the likelihood of early entry. The sign and relative size of all other coefficients in the generic entry equation changes little in comparison to the univariate probit estimates. Generic entry decisions are strongly driven by pre-entry revenues (Pre-entry Market Size). The length of the exclusivity period (Monopoly Duration) also has a significantly positive impact on independent generic entry decisions. Substitutes - the number of available off-patent substitutes measuring the intensity of off-patent competition - generally affects independent generic entry decisions negatively. Both therapeutic and drug form experience encourages generic entry. Early entry decisions in turn are also strongly driven by Pre-entry Market Size. The duration of monopoly affects early entry decisions positively, providing further evidence that Monopoly Duration is not necessarily a good proxy for pioneers' goodwill but rather another market value correlate. Early entry decisions also appear to be negatively affected by the intensity of off-patent competition. The effect of Substitutes is negative, mostly significant, yet smaller in size. Therapeutic field, drug form and year effects are significant in any of the bivariate probit regressions.

Table 7 provides the average marginal effects obtained from the univariate and recursive bivariate probit regressions. The interpretation of average marginal effects facilitates the assessment of the size and economic relevance of the early entry effect. Average marginal effects are reported for the 16 drug markets experiencing early entry between 2002 and 2007, i.e. for the subset of generic entry decisions affected by early entry. The prevailing assumption is that generic manufacturers are apt to correctly anticipate early entry given 
drug markets' characteristics and past experiences. As a result, early entry impairs generic entry only in drug markets which experience early entry. Appendix $[\mathrm{F}]$ provides the average marginal effects computed for all drug markets. The results and conclusions are similar.

Table 7: Univariate \& Recursive Bivariate Probit - Average Marginal Effects

\begin{tabular}{|l|cc|cc|cc|}
\hline \multirow{3}{*}{ Dep.: Generic Entry } & \multicolumn{2}{|c|}{ Data Set 1 $(\mathrm{N}=1581)$} & \multicolumn{2}{c|}{ Data Set $2(\mathrm{~N}=633)$} & \multicolumn{2}{c|}{ Data Set $3(\mathrm{~N}=599)$} \\
& Univariate & Bivariate & Univariate & Bivariate & Univariate & Bivariate \\
& Probit & Probit & Probit & Probit & Probit & Probit \\
\hline \hline Early Entry (0/1) & $-0.0440^{* * *}$ & -0.0522 & $-0.0450^{*}$ & -0.0601 & -0.0402 & -0.0507 \\
& $(0.009)$ & $(0.0344)$ & $(0.021)$ & $(0.0316)$ & $(0.022)$ & $(0.0314)$ \\
Pre-Entry & $0.1089^{* * *}$ & $0.1384^{* * *}$ & $0.2113^{* * *}$ & $0.1762^{* * *}$ & $0.2244^{* * *}$ & $0.1847^{* * *}$ \\
Market Size (log) & $(0.012)$ & $(0.019)$ & $(0.012)$ & $(0.025)$ & $(0.012)$ & $(0.026)$ \\
Monopoly Duration & $0.0228^{* * *}$ & $0.0208^{* * *}$ & $0.0417^{* * *}$ & $0.0389^{* * *}$ & $0.0430^{* * *}$ & $0.0370^{* * *}$ \\
& $(0.003)$ & $(0.004)$ & $(0.004)$ & $(0.007)$ & $(0.005)$ & $(0.008)$ \\
Substitutes & -0.0003 & $-0.0007^{* * *}$ & $-0.0023^{* * *}$ & $-0.0030^{* * *}$ & $-0.0023^{* * *}$ & $-0.0030^{* * *}$ \\
& $(2.1 \mathrm{e}-04)$ & $(2.3 \mathrm{e}-04)$ & $(3.9 \mathrm{e}-04)$ & $(6.2 \mathrm{e}-04)$ & $(4.0 \mathrm{e}-04)$ & $(6.3 \mathrm{e}-04)$ \\
Field Experience & $0.0026^{* * *}$ & $0.0029^{* * *}$ & $0.0023^{* * *}$ & $0.0028^{* * *}$ & $0.0022^{* * *}$ & $0.0028^{* * *}$ \\
& $(3.7 \mathrm{e}-04)$ & $(5.5 \mathrm{e}-04)$ & $(5.5 \mathrm{e}-04)$ & $(7.3 \mathrm{e}-04)$ & $(5.6 \mathrm{e}-04)$ & $(7.5 \mathrm{e}-04)$ \\
Form Experience & $0.0006^{* * *}$ & $0.0005^{* * *}$ & $0.0006^{* * *}$ & $0.0007^{* * *}$ & $0.0006^{* * *}$ & $0.0007^{* * *}$ \\
& $(5.6-05)$ & $(9.3 \mathrm{e}-05)$ & $(8.0 \mathrm{e}-05)$ & $(1.4 \mathrm{e}-04)$ & $(8.3 \mathrm{e}-05)$ & $(1.4 \mathrm{e}-04)$ \\
\hline
\end{tabular}

Notes: Average marginal effects are reported for the subset of sixteen drug markets experiencing early entry between 2002 and 2007. Average marginal effects presented for the univariate (recursive bivariate) probit model denote average, ceteris paribus changes in the likelihood of independent generic entry (conditional on early entry having occured).

The (relative) size of average marginal effects is generally robust to the micro data employed, i.e. the estimates obtained from Data Set 1, Data Set 2 and Data Set 3 reveal a consistent pattern. Univariate probit estimates suggest that early entry lowers the marginal probability of generic entry by about $4 \%$ on average. Except for the estimate obtained for Data Set 3, the average marginal effects are significant at least at the $5 \%$ level. Given the (residual) correlation between generic entry and early entry decisions, univariate probit regressions do not provide consistent estimates, whereas the recursive bivariate probit estimates are consistent. Unlike the average marginal effects obtained from the univariate probit model, the average marginal effects reported for the bivariate probit model denote changes in conditional and not marginal probability of generic entry. When determining the average marginal effect of early entry in the recursive bivariate probit model, interest lies in the average change in the probability of generic entry conditional on early entry having occurred $(P(G=1 \mid E=1))$ and the counterfactual - early entry having not occurred 
$(P(G=1 \mid E=0))$. The average marginal effects of the other covariates similarly denote changes in probability of generic entry given that early entry occurred $(P(G=1 \mid E=1))$. I compute standard errors of the average marginal effects using the delta-method (Papke and Wooldridge, 2005). The relative size of average marginal effects reported for the univariate and recursive bivariate probit models tends to be similar. The average marginal effect of early entry obtained from any of the recursive bivariate probit regressions is insignificant at the $5 \%$ level, however. Accounting for selection, I obtain even stronger evidence that early entry does not significantly lower incentives for independent generic entry. The recursive bivariate probit estimates prove again that Pre-entry Market Size has the strongest impact on generic entry decisions. A mere $1 \%$ increase in drug markets' pre-entry revenues induces on average a $14-18 \%$ increase in the (conditional) probability of independent generic entry. In drug markets experiencing early entry a one standard deviation increase in pre-entry revenues relative to mean pre-entry revenues corresponds to a $4.25 \%$ (Data Set 1: 4.5\%) increase in pre-entry revenues, boosting the likelihood of generic entry by roughly $60-76 \%$.

Furthermore, the (conditional) probability of generic entry tends to increase on average by $0.3 \%(0.07 \%)$ with each retail form launch prior to loss of exclusivity in drug relevant therapeutic fields (using the particular drug's routes of administration). Morton (1999) finds positive effects from therapeutic and drug form experience of a similar magnitude. Given the variation in potential entrants' experience (retail form launches), the economic effect of either therapeutic or drug form experience may not be negligible. A one standard deviation increase in the number of retail form launches in relevant therapeutic fields ${ }^{40}$ increases the likelihood of generic entry by 6.5-9.4\%. Similarly, a one standard deviation increase in the number of retail form launches in relevant therapeutic fields ${ }^{41}$ increases the likelihood of generic entry up to $18.4 \%$. An increase in the duration of the exclusivity period by one year in turn raises the (conditional) probability of generic entry by $2-4 \%$ on average. Given a standard deviation of 1.75 years, the effect tends to be small. Lastly, an increase in the number of off-patent substances by one, reduces the generic entry probability by about 0.1-

\footnotetext{
${ }^{40}$ The standard deviation amounts to $21.8,30.7$ and 31.4 retail form launches in Data Set 1,2 , and 3.

${ }^{41}$ The standard deviation amounts to $126,258.3$ and 262.4 retail form launches in Data Set 1, 2 , and 3.
} 
$0.3 \%$ on average. The effect turns out to be modest given the variation ${ }^{42}$ in the number of off-patent substitutes. The results suggest overall that independent generic entry is primarily influenced by drug markets' pre-entry revenues. Early entry turns out to have no significant effect on generic entry decisions. Figure 2 displays the generic entry patterns in the highrevenue drug markets experiencing early entry. The generic entry patterns observed confirm the notion that drug markets' pre-entry revenues stimulated generic entry greatly.

Figure 2: Generic Entry in Drug Markets experiencing Early Entry
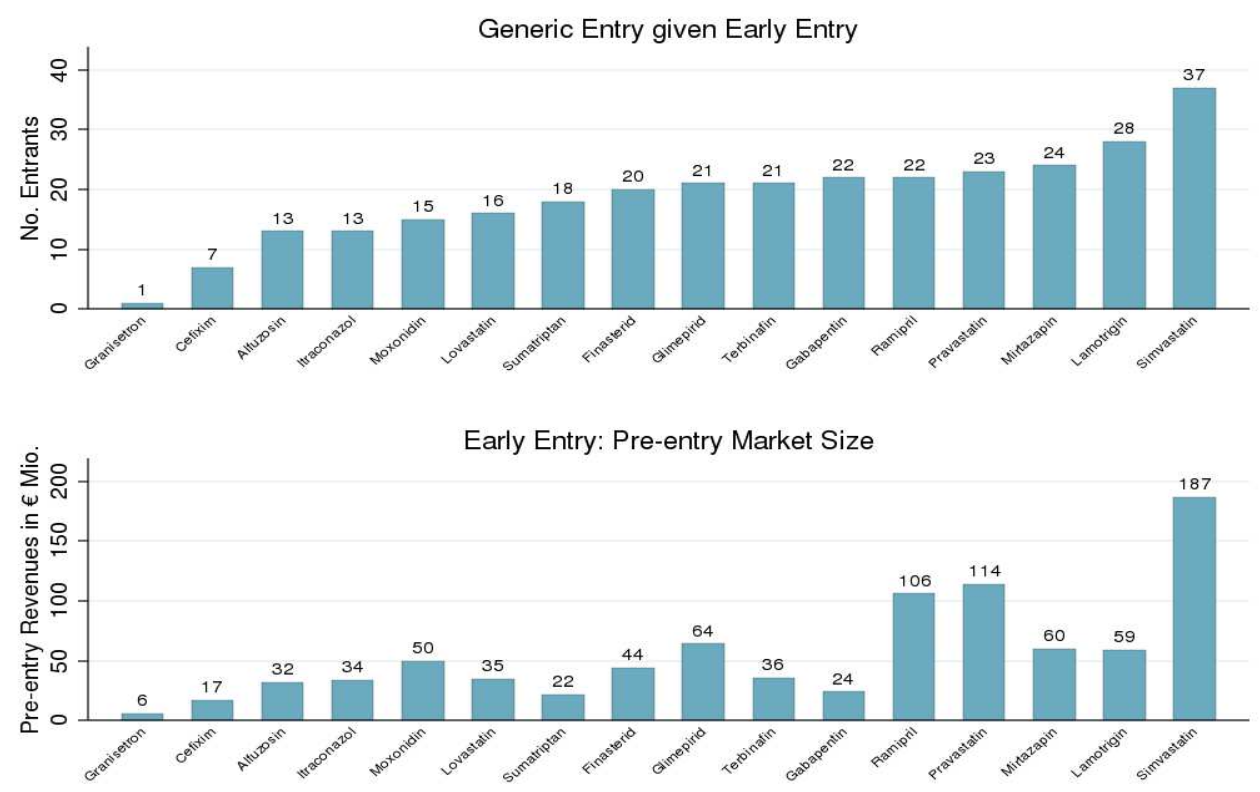

I computed generic firms' market shares in the bestseller segment - the dosage and drug form yielding the largest generic revenues by 2007 - for drug markets experiencing at least one year of off-patent competition. Comparing the turnover and revenue market shares of first-movers entering post loss of exclusivity and those of early entrants, the latter appear to obtain a considerably larger market share with respect to both turnover and revenue. Multiple first generic entry, occurring in the majority of drug markets in Germany post loss of exclusivity, appears to reduce first-mover advantages. Plotting turnover market shares of generic firms against firms' order of entry - including and excluding early entrants in the sample of firms - one finds that generic first-movers entering post loss of exclusivity

\footnotetext{
${ }^{42}$ The standard deviation amounts to roughly 34,37 and 37 substances in Data Set 1, 2, and 3.
} 
tend to nevertheless have a considerable market share advantage over subsequent entrants. Thus, even first-movers entering post loss of exclusivity pose a threat to subsequent generic entrants' profits. Appendix $[\mathrm{G}]$ provides the according graphs. This finding may in turn explain why early entry does not significantly deter independent generic entry. Examining the US pharmaceutical market, Berndt et al. (2007a) find that additional generic entrants after the first four or five generic entrants do not significantly affect long-run generic-tobrand price ratios. A relevant implication of this finding is that a reduction in the number of independent generic firms as a result of early entry is unlikely to substantially impair generic price competition, unless it results in fewer than four or five generic entrants. The generic entry patterns in the majority of drug markets satisfy this criterion, suggesting that the welfare effects of early entry are most likely to be minor. The monotonistic relationship of early entry and pre-entry market revenues - intermediate-sized and high-revenue markets experience early entry proportionally more often - indicate also that original drug producers authorized generic entry prior to loss of exclusivity first and foremost fueled by rent-seeking rather than strategic entry-deterrence motives (Fisher Ellison and Ellison, 2007).

\section{Conclusion}

This study provides recent empirical evidence on the impact of early entry - also known as authorized, branded or pseudo-generic entry - on independent generic entry decisions accounting for the endogeneity of early entry decisions. The results strongly suggest that independent generic entry decisions are primarily influenced by drug markets' pre-entry revenues. Early entry turns out to have no significant impact on independent generic entry decisions. Originators appear to authorize generic entry prior to loss of exclusivity to extract generic profits rather than to deter generic entry. The European Commission's survey of originators conducted in course of its Pharmaceutical Market Sector Inquiry supports this conclusion. Generic first-movers have been shown to enjoy a long-lasting advantage over subsequent generic entrants (Caves et al., 1991; Grabowski and Vernon, 1992; Hollis, 2002) as a result of doctors', patients' and pharmacists' switching costs. Some economists accordingly argue that anticipated early entry has an anti-competitive, deterring effect on independent 
generic entry. Based on a unique micro data set comprising pharmaceutical market and exclusivity data, I examine the impact of early entry on independent generic entry decisions in the German pharmaceutical market within the time period 2002-2007. If generic and early entry occurs in selective drug markets which are more (or less) attractive than given market characteristics suggest (Hollis and Liang, 2006; FTC, 2009), there will be a spurious correlation between early entry and generic entry decisions. Accounting for the endogeneity of early entry decisions, I employ unique micro data and estimate univariate and recursive bivariate probit models of entry. Recursive bivariate probit estimates indicate that early entry decisions are endogeneous, rendering univariate probit estimates inconsistent. The identification strategy in the bivariate probit model relies on the assumption of normality and the fact that I model sequential entry decisions. As early entry decisions are arguably motivated by pioneers' financial distress, I add a count of each original drug producers' further losses of exclusivity between 2002 and 2007 as an instrumental variable to the early entry equation which improves identification. Regardless of the identifying assumption made, I find no evidence that early entry significantly reduces the likelihood of generic entry.

Drug markets' pre-entry revenues influence both independent generic entry and early entry decisions most strongly. Just like previous related studies on generic entry, I also show that the degree of off-patent competition affects generic entry decisions negatively, whereas firms' therapeutic and drug form experiences encourage generic entry. Monopoly duration surprisingly influences generic entry decisions positively and not negatively, indicating that the length of the exclusivity period is not necessarily a good proxy for pioneers' accumulated goodwill stock as suggested by Hurwitz and Caves (1988); Hudson (2000). Generic manufacturers appear to benefit first and foremost if medications are well-established. Government scrutiny targeting early entry would be appropriate if small drug markets turned out to experience early entry more frequently in the future. Further research is also warranted to assess the welfare effects of early entry. Early entry may not impair generic entry decisions, yet it could adversely affect competition in off-patent pharmaceutical markets. Gauging the impact of early entry on generic manufacturers' prices and market shares, and the rate of price erosion, are important areas of research which I intend to examine in the future. 


\section{Appendix}

\section{[A-1] Brand Market Share post Generic Entry - Pfizer (Norvasc)}

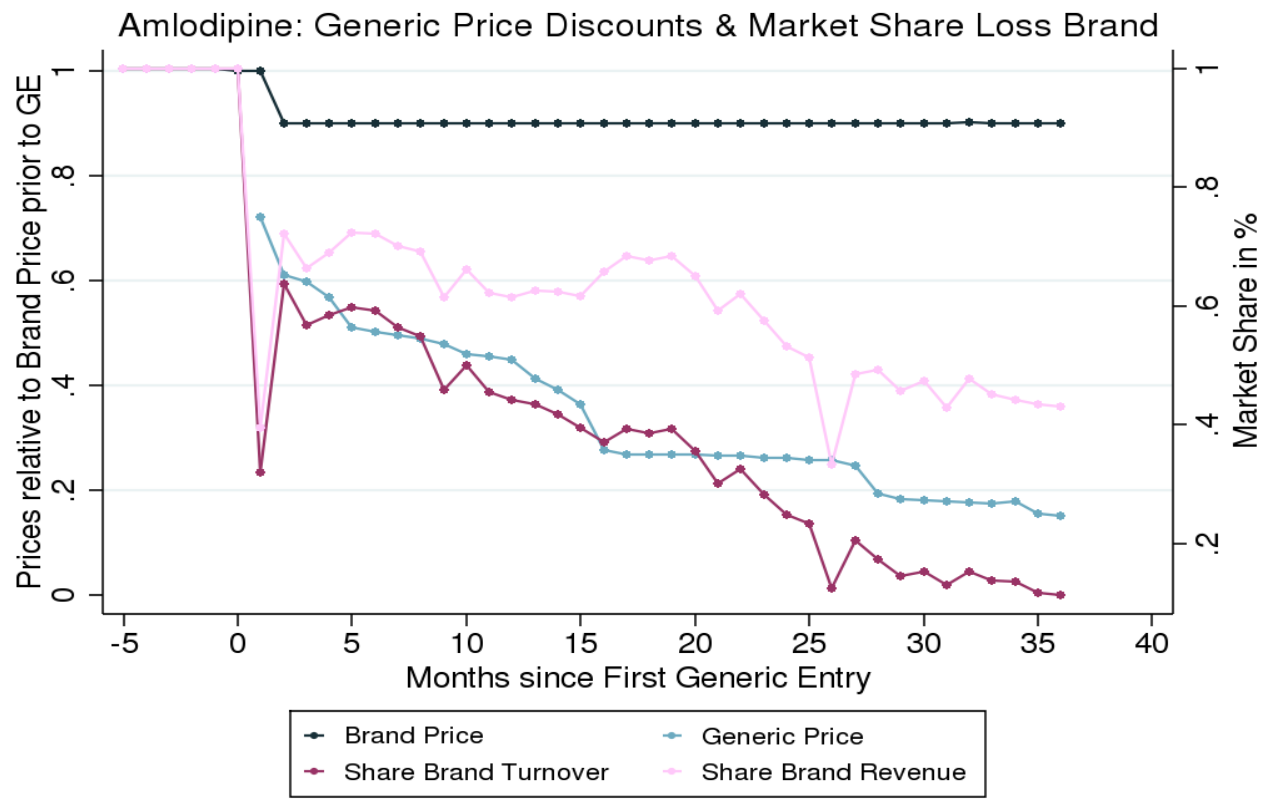

[A-2] Losses of Exclusivity, Early Entry \& Generic Entry 2002-2007

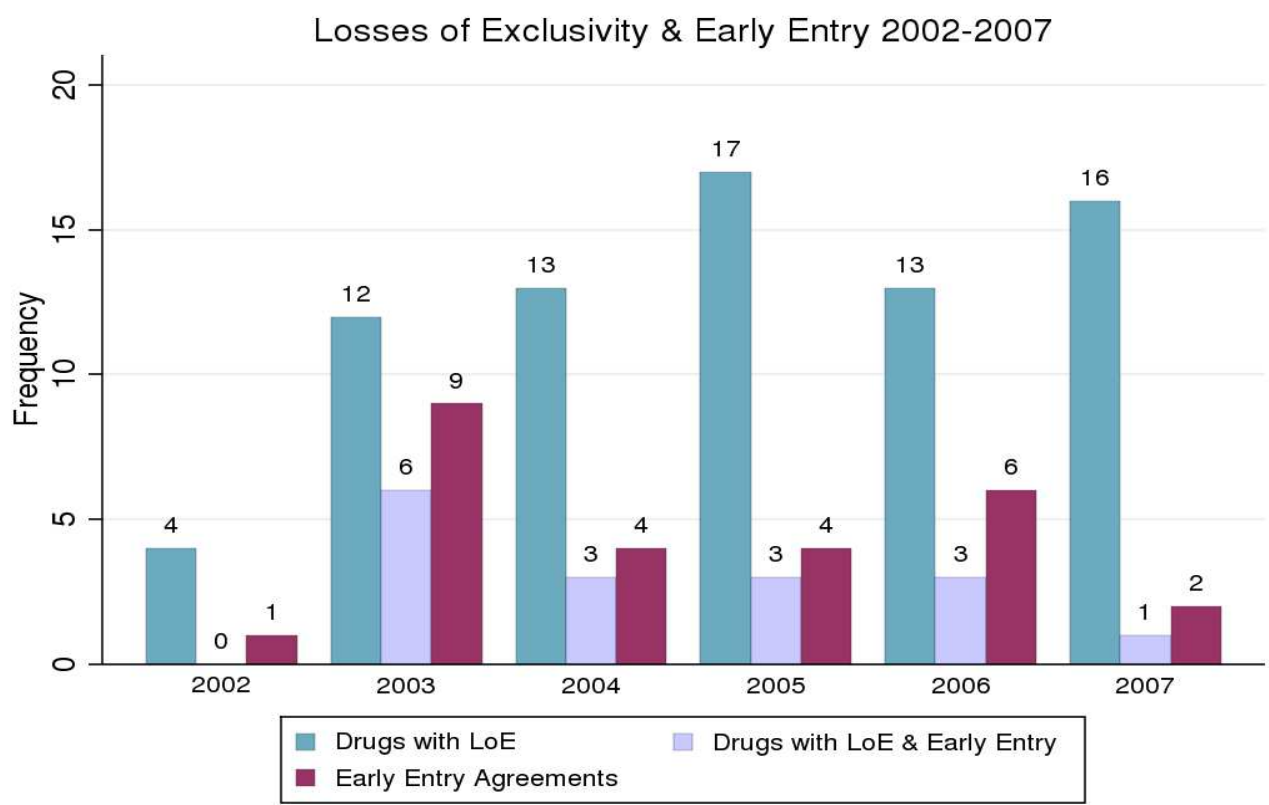



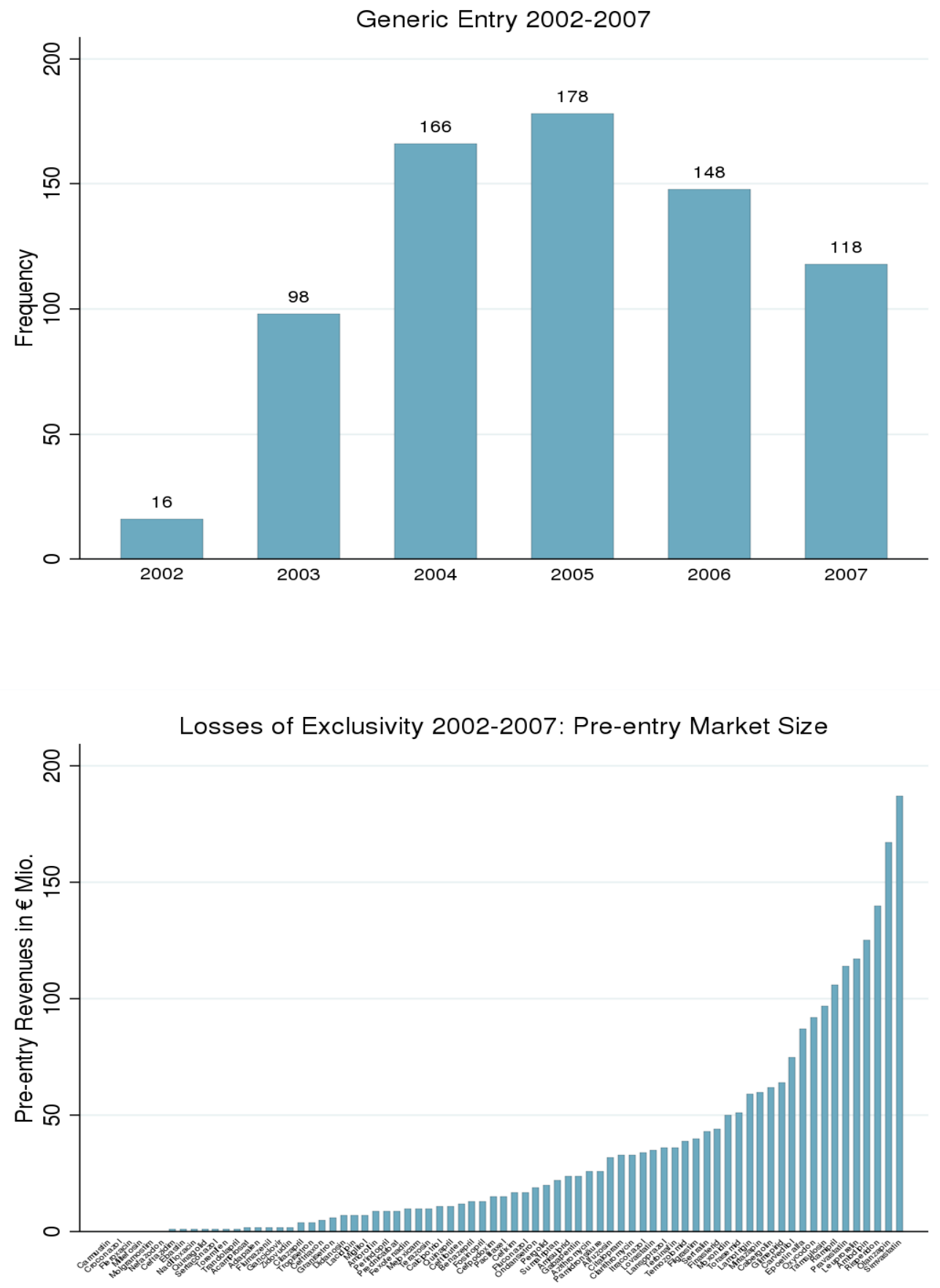
[B] Allocation of Generic Entries and Zero-Entries to Substances

\begin{tabular}{|c|c|c|c|c|c|c|c|c|c|}
\hline Substances & $\begin{array}{c}\text { Generic } \\
\text { Entry }\end{array}$ & $\begin{array}{l}\text { Early } \\
\text { Entry }\end{array}$ & $\begin{array}{c}\text { Generic } \\
\text { Entries }\end{array}$ & Zero-Entries & Total & Zero-Entries & Total & Zero-Entries & Total \\
\hline Acamprosate & no & no & 0 & 100 & 100 & 16 & 16 & 11 & 11 \\
\hline Adapalene & no & no & 0 & 101 & 101 & 23 & 23 & 11 & 11 \\
\hline Alfuzosine & yes & yes & 13 & 87 & 100 & 21 & 34 & 20 & 33 \\
\hline Amisulpride & yes & no & 13 & 86 & 99 & 41 & 54 & 41 & 54 \\
\hline Amlodipine & yes & no & 32 & 70 & 102 & 22 & 54 & 18 & 50 \\
\hline Amorolfine & no & no & 0 & 100 & 100 & 34 & 34 & 33 & 33 \\
\hline Azithromycin & yes & no & 17 & 84 & 101 & 44 & 61 & 44 & 61 \\
\hline Benazepril & yes & no & 8 & 92 & 100 & 37 & 45 & 37 & 45 \\
\hline Cabergoline & yes & no & 8 & 93 & 101 & 29 & 37 & 22 & 30 \\
\hline Calcipotriol & yes & no & 3 & 98 & 101 & 10 & 13 & 10 & 13 \\
\hline Carmustine & no & no & 0 & 101 & 101 & 16 & 16 & 15 & 15 \\
\hline Carvedilole & yes & no & 25 & 75 & 100 & 22 & 47 & 22 & 47 \\
\hline Cefixime & yes & yes & 7 & 89 & 96 & 51 & 58 & 51 & 58 \\
\hline Cefpodoxime & yes & no & 10 & 90 & 100 & 49 & 59 & 47 & 57 \\
\hline Ceftazidime & yes & no & 6 & 95 & 101 & 52 & 58 & 14 & 20 \\
\hline Ceftibuten & no & no & 0 & 101 & 101 & 61 & 61 & 59 & 59 \\
\hline Ceftriaxone & yes & no & 10 & 92 & 102 & 48 & 58 & 12 & 22 \\
\hline Cilazapril & no & no & 0 & 100 & 100 & 45 & 45 & 45 & 45 \\
\hline Citalopram & yes & no & 28 & 70 & 98 & 12 & 40 & 12 & 40 \\
\hline Clarithromycin & yes & no & 18 & 83 & 101 & 42 & 60 & 42 & 60 \\
\hline Croconazole & no & no & 0 & 100 & 100 & 34 & 34 & 33 & 33 \\
\hline Didanosine & no & no & 0 & 101 & 101 & 22 & 22 & 21 & 21 \\
\hline Ebastine & no & no & 0 & 100 & 100 & 31 & 31 & 30 & 30 \\
\hline Epoetin alfa & yes & no & 3 & 98 & 101 & 20 & 23 & 5 & 8 \\
\hline Fexofenadine & no & no & 0 & 100 & 100 & 31 & 31 & 30 & 30 \\
\hline Filgrastim & no & no & 0 & 101 & 101 & 4 & 4 & 3 & 3 \\
\hline Finasteride & yes & yes & 20 & 80 & 100 & 24 & 44 & 16 & 36 \\
\hline Fleroxacin & no & no & 0 & 101 & 101 & 60 & 60 & 57 & 57 \\
\hline Fluconazole & yes & no & 19 & 81 & 100 & 3 & 22 & 3 & 22 \\
\hline Flumazenile & yes & no & 5 & 98 & 103 & 15 & 20 & 6 & 11 \\
\hline Fosinopril & yes & no & 3 & 97 & 100 & 42 & 45 & 42 & 45 \\
\hline Gabapentin & yes & yes & 22 & 76 & 98 & 10 & 32 & 8 & 30 \\
\hline Ganciclovir & no & no & 0 & 101 & 101 & 34 & 34 & 34 & 34 \\
\hline Glimepirid & yes & yes & 21 & 79 & 100 & 20 & 41 & 20 & 41 \\
\hline Granisetron & yes & yes & 1 & 97 & 98 & 18 & 19 & 17 & 18 \\
\hline Itraconazole & yes & yes & 13 & 85 & 98 & 5 & 18 & 5 & 18 \\
\hline
\end{tabular}




\begin{tabular}{|c|c|c|c|c|c|c|c|c|c|}
\hline \multirow[b]{2}{*}{ Substances } & \multirow{2}{*}{$\begin{array}{c}\text { Generic } \\
\text { Entry }\end{array}$} & \multirow{2}{*}{$\begin{array}{l}\text { Early } \\
\text { Entry }\end{array}$} & \multirow{2}{*}{$\begin{array}{l}\text { Generic } \\
\text { Entries }\end{array}$} & \multicolumn{2}{|c|}{$\underline{\text { Data Set } 1}$} & \multicolumn{2}{|c|}{ Data Set 2} & \multicolumn{2}{|c|}{$\underline{\text { Data Set } 3}$} \\
\hline & & & & Zero-Entries & Total & Zero-Entries & Total & Zero-Entries & Total \\
\hline Lacidipine & no & no & 0 & 101 & 101 & 54 & 54 & 50 & 50 \\
\hline Lamotrigine & yes & yes & 28 & 71 & 99 & 22 & 50 & 20 & 48 \\
\hline Lansoprazole & yes & no & 13 & 88 & 101 & 37 & 50 & 35 & 48 \\
\hline Leuprorelin & yes & no & 2 & 99 & 101 & 31 & 33 & 1 & 3 \\
\hline Lovastatin & yes & yes & 16 & 81 & 97 & 19 & 35 & 14 & 30 \\
\hline Meloxicam & yes & no & 11 & 89 & 100 & 47 & 58 & 46 & 57 \\
\hline Miglitol & no & no & 0 & 98 & 98 & 37 & 37 & 37 & 37 \\
\hline Miltefosine & no & no & 0 & 101 & 101 & 17 & 17 & 3 & 3 \\
\hline Mirtazapine & yes & yes & 24 & 74 & 98 & 19 & 43 & 19 & 43 \\
\hline Molgramostim & no & no & 0 & 101 & 101 & 4 & 4 & 3 & 3 \\
\hline Moxonidine & yes & yes & 15 & 83 & 98 & 14 & 29 & 14 & 29 \\
\hline Nadifloxacin & no & no & 0 & 101 & 101 & 23 & 23 & 11 & 11 \\
\hline Nefazodone & no & no & 0 & 101 & 101 & 45 & 45 & 44 & 44 \\
\hline Olanzapine & yes & no & 7 & 94 & 101 & 49 & 56 & 49 & 56 \\
\hline Ondansetron & yes & no & 20 & 88 & 108 & 11 & 31 & 10 & 30 \\
\hline Oxycodone & yes & no & 4 & 97 & 101 & 60 & 64 & 54 & 58 \\
\hline Paclitaxel & yes & no & 10 & 92 & 102 & 7 & 17 & 6 & 16 \\
\hline Pamidron acid & yes & no & 7 & 93 & 100 & 5 & 12 & 1 & 8 \\
\hline Pergolide & yes & no & 9 & 90 & 99 & 19 & 28 & 19 & 28 \\
\hline Perindopril & no & no & 0 & 98 & 98 & 43 & 43 & 43 & 43 \\
\hline Pravastatin & yes & yes & 23 & 74 & 97 & 15 & 38 & 12 & 35 \\
\hline Prednicarbate & yes & no & 2 & 96 & 98 & 22 & 24 & 22 & 24 \\
\hline Quinagolid & no & no & 0 & 101 & 101 & 22 & 22 & 16 & 16 \\
\hline Quinapril & yes & no & 9 & 90 & 99 & 35 & 44 & 35 & 44 \\
\hline Ramipril & yes & yes & 22 & 77 & 99 & 22 & 44 & 22 & 44 \\
\hline Risperidone & yes & no & 29 & 72 & 101 & 30 & 59 & 29 & 58 \\
\hline Sertaconazole & no & no & 0 & 101 & 101 & 34 & 34 & 33 & 33 \\
\hline Sertraline & yes & no & 25 & 76 & 101 & 19 & 44 & 18 & 43 \\
\hline Simvastatin & yes & yes & 37 & 66 & 103 & 7 & 44 & 4 & 41 \\
\hline Sumatriptan & yes & yes & 18 & 81 & 99 & 44 & 62 & 37 & 55 \\
\hline Tamsulosin & yes & no & 27 & 76 & 103 & 11 & 38 & 10 & 37 \\
\hline Temozolomide & no & no & 0 & 101 & 101 & 16 & 16 & 5 & 5 \\
\hline Terazosin & yes & no & 20 & 79 & 99 & 22 & 42 & 22 & 42 \\
\hline Terbinafine & yes & yes & 21 & 80 & 101 & 21 & 42 & 19 & 40 \\
\hline Torasemide & yes & no & 20 & 80 & 100 & 26 & 46 & 26 & 46 \\
\hline Toremifene & no & no & 0 & 98 & 98 & 29 & 29 & 29 & 29 \\
\hline Trandolapril & no & no & 0 & 101 & 101 & 49 & 49 & 49 & 49 \\
\hline Tropisetron & no & no & 0 & 101 & 101 & 23 & 23 & 22 & 22 \\
\hline Zidovudine & no & no & 0 & 101 & 101 & 22 & 22 & 22 & 22 \\
\hline
\end{tabular}




\section{[C-1] Summary Statistics Data Set1}

\begin{tabular}{|l|cccccc|}
\hline Variable Name & Mean & Median & Min. & Max. & Sd. & N \\
\hline \hline Generic Entry & 0.10 & 0 & 0 & 1 & - & 7517 \\
Early Entry & 0.21 & 0 & 0 & 1 & - & 7517 \\
Pre-Entry Market Size (€ Mio.) & 32.8 & 14.8 & 0 & 187 & 41.5 & 7517 \\
Pre-Entry Market Size (log) & 15.76 & 16.51 & 0 & 19.05 & 3.40 & 7517 \\
Monopoly Duration & 12.12 & 12.5 & 5 & 20 & 3.27 & 7517 \\
Substitutes & 47.86 & 39 & 8 & 204 & 34.91 & 7517 \\
Field Experience & 9.39 & 0 & 0 & 374 & 25.40 & 7517 \\
Form Experience & 84.19 & 26 & 0 & 1679 & 157.00 & 7517 \\
Financial Distress & 2.95 & 2 & 0 & 6 & 2.43 & 7517 \\
\hline
\end{tabular}

\section{[C-2] Summary Statistics Data Set2}

\begin{tabular}{|l|cccccc|}
\hline Variable Name & Mean & Median & Min. & Max. & Sd. & N \\
\hline \hline Generic Entry & 0.26 & 0 & 0 & 1 & - & 2804 \\
Early Entry & 0.23 & 0 & 0 & 1 & - & 2804 \\
Pre-Entry Market Size (€ Mio.) & 37.3 & 19.1 & 0 & 187 & 44.6 & 2804 \\
Pre-Entry Market Size (log) & 16.05 & 16.76 & 0 & 19.05 & 3.15 & 2804 \\
Monopoly Duration & 12.12 & 12.5 & 5 & 20 & 3.23 & 2804 \\
Substitutes & 54.51 & 44 & 8 & 204 & 35.81 & 2804 \\
Field Experience & 25.18 & 11 & 0 & 374 & 36.50 & 2804 \\
Form Experience & 165.21 & 75 & 0 & 1679 & 218.67 & 2804 \\
Financial Distress & 2.94 & 2 & 0 & 6 & 2.46 & 2804 \\
\hline
\end{tabular}




\section{[D] Univariate Probit (incl. Instrument) - Coefficients}

\begin{tabular}{|c|c|c|c|}
\hline & $\begin{array}{c}\text { Data Set } 1(\mathrm{~N}=7517) \\
\text { Generic Entry }\end{array}$ & $\begin{array}{c}\text { Data Set } 2(\mathrm{~N}=2804) \\
\text { Generic Entry }\end{array}$ & $\begin{array}{c}\text { Data Set } 3(\mathrm{~N}=2531) \\
\text { Generic Entry }\end{array}$ \\
\hline Early Entry $(0 / 1)$ & $\begin{array}{c}-0.2157^{* * *} \\
(0.055)\end{array}$ & $\begin{array}{c}-0.1534^{*} \\
(0.074)\end{array}$ & $\begin{array}{l}-0.1390 \\
(0.076)\end{array}$ \\
\hline $\begin{array}{l}\text { Pre-Entry } \\
\text { Market Size (log) }\end{array}$ & $\begin{array}{c}0.5797^{* * *} \\
(0.045)\end{array}$ & $\begin{array}{c}0.7328^{* * *} \\
(0.049)\end{array}$ & $\begin{array}{c}0.7743^{* * *} \\
(0.049)\end{array}$ \\
\hline Monopoly Duration & $\begin{array}{c}0.1218^{* * *} \\
(0.014)\end{array}$ & $\begin{array}{c}0.1441^{* * *} \\
(0.016)\end{array}$ & $\begin{array}{c}0.1482^{* * *} \\
(0.017)\end{array}$ \\
\hline Substitutes & $\begin{array}{r}-0.0018 \\
(0.001)\end{array}$ & $\begin{array}{c}-0.0084^{* * *} \\
(0.001)\end{array}$ & $\begin{array}{c}-0.0079^{* * *} \\
(0.001)\end{array}$ \\
\hline Field Experience & $\begin{array}{c}0.0139^{* * *} \\
(0.002)\end{array}$ & $\begin{array}{c}0.0078^{* * *} \\
(0.001)\end{array}$ & $\begin{array}{c}0.0075^{* * *} \\
(0.002)\end{array}$ \\
\hline Form Experience & $\begin{array}{c}0.0030 * * * \\
(3.1 \mathrm{e}-04)\end{array}$ & $\begin{array}{c}0.0023^{* * *} \\
(3.4 \mathrm{e}-04)\end{array}$ & $\begin{array}{c}0.0022^{* * *} \\
(3.4 \mathrm{e}-04)\end{array}$ \\
\hline Financial Distress & $\begin{array}{l}0.0015 \\
(0.012)\end{array}$ & $\begin{array}{r}-0.0168 \\
(0.014)\end{array}$ & $\begin{array}{r}-0.0020 \\
(0.015)\end{array}$ \\
\hline Therap. Field $(0 / 1)$ & yes & yes & yes \\
\hline Drug Form $(0 / 1)$ & yes & yes & yes \\
\hline Year Expiry $(0 / 1)$ & yes & yes & yes \\
\hline Const. & $-11.4209^{* * *}$ & $-13.0998^{* * *}$ & $-13.6102^{* * *}$ \\
\hline $\begin{array}{l}\text { Prob > chi2 }(24) \\
\text { Log-Likelihood }\end{array}$ & $\begin{array}{c}<0.001 \\
-1403.63\end{array}$ & $\begin{array}{l}<0.001 \\
-977.68\end{array}$ & $\begin{array}{l}<0.001 \\
-914.90\end{array}$ \\
\hline
\end{tabular}

Notes: An observation in the regression is the decision of a generic firm to enter a drug market post loss of exclusivity (generic entry). Heteroskedasticity-robust and clustered standard errors in parentheses. Oral drugs in parasitology and sense organs with loss of exclusivity in 2002 form the reference group in generic entry equations. 
[E-1] Recursive Bivariate Probit (excl. Instrument) - Coefficients

\begin{tabular}{|c|c|c|c|c|c|c|}
\hline & \multicolumn{2}{|c|}{ Data Set $1(N=7517)$} & \multicolumn{2}{|c|}{ Data Set $2(N=2804)$} & \multicolumn{2}{|c|}{ Data Set $3(N=2531)$} \\
\hline & $\begin{array}{l}\text { Generic } \\
\text { Entry }\end{array}$ & $\begin{array}{l}\text { Early } \\
\text { Entry }\end{array}$ & $\begin{array}{l}\text { Generic } \\
\text { Entry }\end{array}$ & $\begin{array}{l}\text { Early } \\
\text { Entry }\end{array}$ & $\begin{array}{l}\text { Generic } \\
\text { Entry }\end{array}$ & $\begin{array}{l}\text { Early } \\
\text { Entry }\end{array}$ \\
\hline Early Entry $(0 / 1)$ & $\begin{array}{c}-1.6293^{* * *} \\
(0.062)\end{array}$ & & $\begin{array}{c}-1.5228^{* * *} \\
(0.053)\end{array}$ & & $\begin{array}{c}-1.5034^{* * *} \\
(0.054)\end{array}$ & \\
\hline $\begin{array}{l}\text { Pre-Entry } \\
\text { Market Size (log) }\end{array}$ & $\begin{array}{c}0.7987^{* * *} \\
(0.033)\end{array}$ & $\begin{array}{c}0.7867^{* * *} \\
(0.011)\end{array}$ & $\begin{array}{c}0.9086^{* * *} \\
(0.044)\end{array}$ & $\begin{array}{c}0.8634^{* * *} \\
(0.037)\end{array}$ & $\begin{array}{c}0.9739^{* * *} \\
(0.043)\end{array}$ & $\begin{array}{c}0.9209^{* * *} \\
(0.043)\end{array}$ \\
\hline Monopoly Duration & $\begin{array}{c}0.0531^{* * *} \\
(0.009)\end{array}$ & $\begin{array}{c}0.1053^{* * *} \\
(0.002)\end{array}$ & $\begin{array}{c}0.1430^{* * *} \\
(0.012)\end{array}$ & $\begin{array}{c}0.0888^{* * *} \\
(0.010)\end{array}$ & $\begin{array}{c}0.1551^{* * *} \\
(0.013)\end{array}$ & $\begin{array}{c}0.1160^{* * *} \\
(0.011)\end{array}$ \\
\hline Substitutes & $\begin{array}{c}-0.0035^{* * *} \\
(0.001)\end{array}$ & $\begin{array}{c}-0.0022^{* * *} \\
(1.7 \mathrm{e}-04)\end{array}$ & $\begin{array}{c}-0.0064^{* * *} \\
(0.001)\end{array}$ & $\begin{array}{l}0.0003 \\
(0.010)\end{array}$ & $\begin{array}{c}-0.0071^{* * *} \\
(0.001)\end{array}$ & $\begin{array}{l}-0.0011 \\
(0.001)\end{array}$ \\
\hline Field Experience & $\begin{array}{c}0.0121^{* * *} \\
(0.002)\end{array}$ & - & $\begin{array}{c}0.0069^{* * *} \\
(0.001)\end{array}$ & - & $\begin{array}{c}0.0068^{* * *} \\
(0.001)\end{array}$ & - \\
\hline Form Experience & $\begin{array}{c}0.0021^{* * *} \\
(2.7 \mathrm{e}-04)\end{array}$ & - & $\begin{array}{c}0.0016^{* * *} \\
(2.5 \mathrm{e}-04)\end{array}$ & - & $\begin{array}{c}0.0016^{* * *} \\
(2.6 \mathrm{e}-04)\end{array}$ & - \\
\hline Therap. Field $(0 / 1)$ & yes & yes & yes & yes & yes & yes \\
\hline Drug Form (0/1) & yes & no & yes & no & yes & no \\
\hline Year Expiry (0/1) & yes & yes & yes & yes & yes & yes \\
\hline Const. & $-14.5317^{* * *}$ & $-14.6976^{* * *}$ & $-16.0689^{* * *}$ & $-16.5732^{* * *}$ & $-17.0781^{* * *}$ & $-17.6726^{* * *}$ \\
\hline Prob $>\operatorname{chi} 2(35)$ & $<0$ & & & 001 & & \\
\hline Log-Likelihood & -390 & .83 & -19 & 9.02 & -17 & .76 \\
\hline$\rho$ & 0.92 & $9^{* * *}$ & 0.93 & $3^{* * *}$ & 0.93 & $2^{* * *}$ \\
\hline Wald Test: chi2(1) & & & & .04 & & \\
\hline Prob > $\operatorname{chi} 2(1)$ & $<0$ & & & 001 & & \\
\hline
\end{tabular}

Notes: In columns (1), (3) and (5) an observation in the regression is the decision of a generic firm to enter a drug market post loss of exclusivity (generic entry). In columns (2), (4) and (6) the occurrence of early entry prior to loss of exclusivity denotes the dependent variable. Heteroskedasticity-robust and clustered standard errors in parentheses. Oral drugs in parasitology and sense organs with loss of exclusivity in 2002 form the reference group in the generic entry equation. The Wald Test is conducted for the null hypothesis of $\rho=0$, i.e. absence of correlation in the model.

\section{[E-2] Likelihood-ratio test: Restricted vs. Unrestricted Model}

\begin{tabular}{|c|c|c|c|c|c|c|}
\hline \multirow[b]{2}{*}{ Model } & \multicolumn{2}{|c|}{ Data Set $1(\mathrm{~N}=7517)$} & \multicolumn{2}{|c|}{ Data Set $2(\mathrm{~N}=2804)$} & \multicolumn{2}{|c|}{ Data Set $3(N=2531)$} \\
\hline & Restricted & Unrestricted & Restricted & Unrestricted & Restricted & Unrestricted \\
\hline Log-Likelihood & -3903.83 & -3870.52 & -1919.02 & -1903.42 & -1789.76 & -1775.53 \\
\hline LR $\operatorname{chi} 2(1)$ & \multicolumn{2}{|c|}{66.62} & \multicolumn{2}{|c|}{31.20} & \multicolumn{2}{|c|}{28.45} \\
\hline Prob > chi 2 & \multicolumn{2}{|c|}{$<0.001$} & \multicolumn{2}{|c|}{$<0.001$} & \multicolumn{2}{|c|}{$<0.001$} \\
\hline
\end{tabular}


[F] Univariate \& Rec. Bivariate Probit - Avg. Marginal Effects (All Drugs)

\begin{tabular}{|c|c|c|c|c|c|c|}
\hline \multirow[b]{2}{*}{ Dep.: Generic Entry } & \multicolumn{2}{|c|}{ Data Set $1(\mathrm{~N}=7517)$} & \multicolumn{2}{|c|}{ Data Set $2(N=2804)$} & \multicolumn{2}{|c|}{ Data Set $3(N=2531)$} \\
\hline & $\begin{array}{l}\text { Univariate } \\
\text { Probit }\end{array}$ & $\begin{array}{c}\text { Bivariate } \\
\text { Probit }\end{array}$ & $\begin{array}{l}\text { Univariate } \\
\text { Probit }\end{array}$ & $\begin{array}{l}\text { Bivariate } \\
\text { Probit }\end{array}$ & $\begin{array}{l}\text { Univariate } \\
\text { Probit }\end{array}$ & $\begin{array}{c}\text { Bivariate } \\
\text { Probit }\end{array}$ \\
\hline Early Entry $(0 / 1)$ & $\begin{array}{c}-0.0215^{* * *} \\
(0.005)\end{array}$ & $\begin{array}{l}-0.0122 \\
(0.019)\end{array}$ & $\begin{array}{c}-0.0298^{*} \\
(0.014)\end{array}$ & $\begin{array}{l}0.0375 \\
(0.045)\end{array}$ & $\begin{array}{l}-0.0278 \\
(0.015)\end{array}$ & $\begin{array}{l}0.0484 \\
(0.045)\end{array}$ \\
\hline $\begin{array}{l}\text { Pre-Entry } \\
\text { Market Size (log) }\end{array}$ & $\begin{array}{c}0.0597^{* * *} \\
(0.006)\end{array}$ & $\begin{array}{c}0.0676^{* * *} \\
(0.016)\end{array}$ & $\begin{array}{c}0.1441^{* * * *} \\
(0.010)\end{array}$ & $\begin{array}{c}0.1230^{* * *} \\
(0.025)\end{array}$ & $\begin{array}{c}0.1578^{* * *} \\
(0.009)\end{array}$ & $\begin{array}{c}0.1328^{* * *} \\
(0.026)\end{array}$ \\
\hline Monopoly Duration & $\begin{array}{c}0.0125^{* * *} \\
(0.002)\end{array}$ & $\begin{array}{c}0.0110^{* * *} \\
(0.002)\end{array}$ & $\begin{array}{c}0.0284^{* * *} \\
(0.003)\end{array}$ & $\begin{array}{c}0.0310^{* * *} \\
(0.009)\end{array}$ & $\begin{array}{c}0.0303^{* * *} \\
(0.003)\end{array}$ & $\begin{array}{c}0.0286^{* * *} \\
(0.008)\end{array}$ \\
\hline Substitutes & $\begin{array}{c}-0.0002 \\
(1.2 \mathrm{e}-04)\end{array}$ & $\begin{array}{l}-0.0003^{*} \\
(1.4 \mathrm{e}-04)\end{array}$ & $\begin{array}{c}-0.0016^{* * *} \\
(8.5 \mathrm{e}-04)\end{array}$ & $\begin{array}{c}-0.0026^{* * *} \\
(7.8 \mathrm{e}-04)\end{array}$ & $\begin{array}{c}-0.0016^{* * *} \\
(8.5 \mathrm{e}-04)\end{array}$ & $\begin{array}{c}-0.0027^{* * *} \\
(7.5 \mathrm{e}-04)\end{array}$ \\
\hline Field Experience & $\begin{array}{c}0.0014^{* * *} \\
(1.9 \mathrm{e}-04)\end{array}$ & $\begin{array}{c}0.0016^{* * *} \\
(4.1 \mathrm{e}-04)\end{array}$ & $\begin{array}{c}0.0015^{* * *} \\
(3.6 \mathrm{e}-04)\end{array}$ & $\begin{array}{l}0.0025^{* *} \\
(8.7 \mathrm{e}-04)\end{array}$ & $\begin{array}{c}0.0015^{* * *} \\
(2.8 \mathrm{e}-04)\end{array}$ & $\begin{array}{l}0.0025^{* *} \\
(8.9 \mathrm{e}-04)\end{array}$ \\
\hline Form Experience & $\begin{array}{c}0.0003^{* * *} \\
(2.9 \mathrm{e}-05)\end{array}$ & $\begin{array}{c}0.0003^{* * *} \\
(7.4 \mathrm{e}-05)\end{array}$ & $\begin{array}{c}0.0004^{* * *} \\
(5.7 \mathrm{e}-05)\end{array}$ & $\begin{array}{l}0.0006^{* *} \\
(1.9 \mathrm{e}-04)\end{array}$ & $\begin{array}{c}0.0004^{* * *} \\
(6.1 \mathrm{e}-05)\end{array}$ & $\begin{array}{l}0.0006^{* *} \\
(1.9 \mathrm{e}-04)\end{array}$ \\
\hline
\end{tabular}

$* \mathrm{p}<0.05,{ }^{* *} \mathrm{p}<0.01,{ }^{* * *} \mathrm{p}<0.001$

Notes: Average marginal effects are reported for the 75 drug markets experiencing a loss of exclusivity between 2002 and 2007. Average marginal effects presented for the univariate (recursive bivariate) probit model denote average, ceteris paribus changes in the likelihood of independent generic entry (conditional on early entry having occured).

[G] Generic Market Shares \& Entry Order (Bestseller Segment)
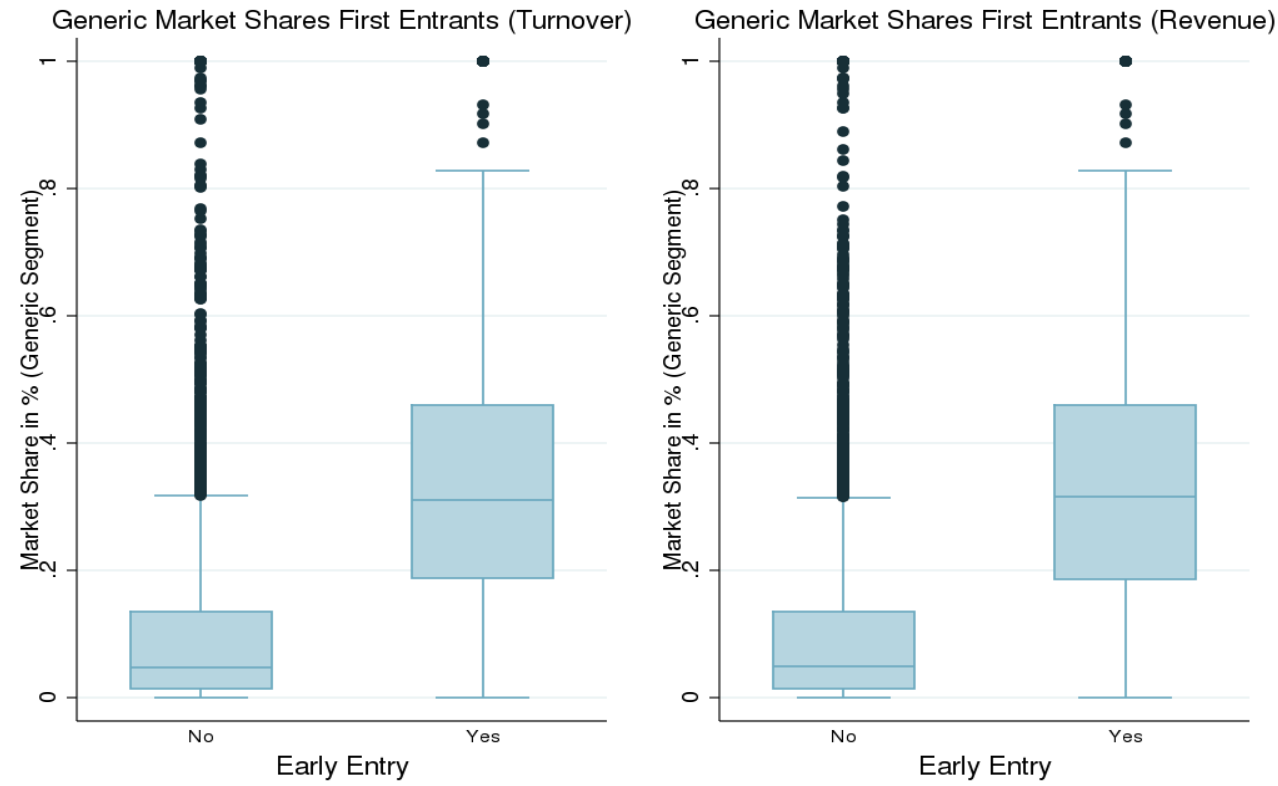


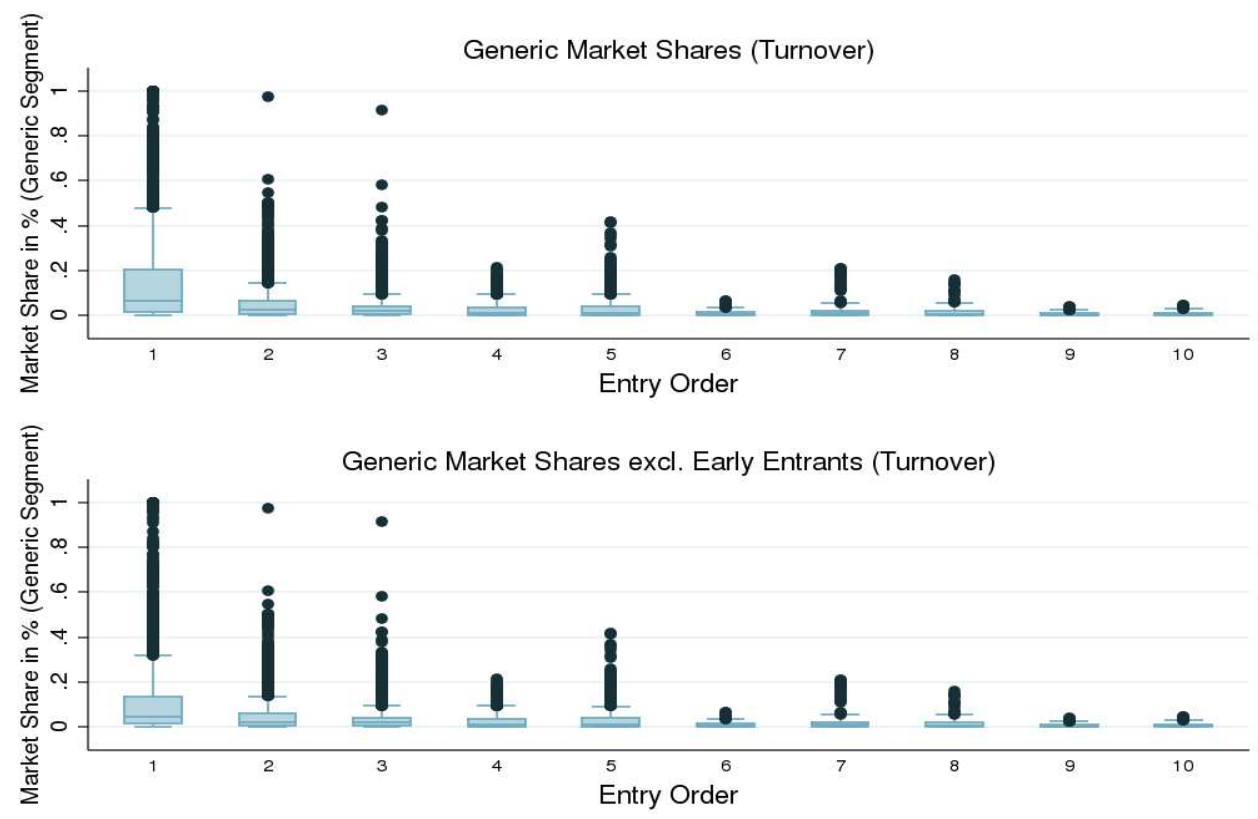

\section{References}

Accenture (2005). "Die Bedeutung der Generikaindustrie für die Gesundheitsversorgung in Deutschland."

acis Arzneimittel GmbH (2007). "Generika in Deutschland." Company Website.

Berndt ER, Kyle MK, Ling DC (2002). "Deregulating Direct-to-Consumer Marketing of Prescription Drugs: Effects on Prescription and Over-the-Counter Product Sales." Journal of Law and Economics, 45(2), 691-723.

Berndt ER, Kyle MK, Ling DC (2003). "The Long Shadow of Patent Expiration: Generic Entry and Rx-to-OTC Switches." NBER Studies in Income and Wealth v.64 - Scanner Data and Price Indexes, pp. 229-273.

Berndt ER, Mortimer R, Bhattacharjya A, Parece A, Tuttle E (2007a). "Authorized Generic Drugs, Price Competition, and Consumers' Welfare." Health Affairs, 26(3), 790-799.

Berndt ER, Mortimer R, Parece A (2007b). "Do Authorized Generic Drugs Deter Paragraph IV Certifications? Recent Evidence." Working Paper.

Bhattacharya J, Goldman DP, McCaffrey DF (2006). "Estimating Probit Models with SelfSelected Treatments." Statistics in Medicine, 25, 389-413.

Caves RE, Whinston MD, Hurwitz M, Pakes A, Temin P (1991). "Patent Expiration, Entry, and Competition in the U.S. Pharmaceutical Industry." Brookings Papers on Economic Activity. Microeconomics, 1991, 1-66. 
EUC (2008). "European Commission: Pharmaceutical Sector Inquiry - Preliminary Report."

EUC (2009). "European Commission: Pharmaceutical Sector Inquiry - Final Report."

Evans WN, Schwab RM (1995). "Finishing High School and Starting College: Do Catholic Schools Make a Difference?" The Quarterly Journal of Economics, 110(4), 941-974.

Fisher Ellison S, Ellison G (2007). "Strategic Entry Deterrence and the Behavior of Pharmaceutical Incumbents Prior to Patent Expiration." NBER Working Paper No. W13069.

FTC (2002). "Federal Trade Commission: Generic Drug Entry Prior to Patent Expiration - An FTC Study."

FTC (2009). "Federal Trade Commission: Authorized Generics - An Interim Report."

Goldman DP, Bhattacharya J, McCaffrey DF, Duan N, Leibowitz AA, Joyce GF, Morton SC (2001). "Effect of Insurance on Mortality in an HIV-Positive Population in Care." Journal of the American Statistical Association, 96, 883-894.

Grabowski HG, Kyle MK (2007). "Generic Competition and Market Exclusivity in Pharmaceuticals." Managerial and Decision Economics, 28, 491-502.

Grabowski HG, Vernon JM (1992). "Brand Loyalty, Entry, and Price Competition in Pharmaceuticals after the 1984 Drug Act." Journal of Law and Economics, 35, 331-350.

Greene WH (2008). Econometric Analysis - Sixth Edition. Pearson Prentice Hall.

Hollis A (2002). "The Importance of Being First: Evidence from Canadian Generic Pharmaceuticals." Health Economics, 11, 723-734.

Hollis A (2003). "The Anti-Competitive Effects of Brand-Controlled "Pseudo-Generics" in the Canadian Pharmaceutical Market." Canadian Public Policy / Analyse de Politiques, 29, 21-32.

Hollis A, Liang BA (2006). "An Assessment of the Effect of Authorized Generics on Consumer Prices." Working Paper.

Hudson J (2000). "Generic Take-up in the Pharmaceutical Market following Patent Expiry - A Multi-Country Study." International Review of Law and Economics, 20, 205-221.

Hurwitz MA, Caves RE (1988). "Persuasion or Information? Promotion and the Shares of Brand Name and Generic Pharmaceuticals." Journal of Law and Economics, 31, 299-320.

Janakiraman R, Dutta S, Sismeiro C, Stern P (2008). "Physicians' Persistence and Its Implications for Their Response to Promotion of Prescription Drugs." Management Science, 54, 1080-1093.

Jones AM, Xander K, van Doorslaer E (2006). "The Impact of Having Supplementary Private Health Insurance on the Use of Specialists." Annales D'Économie et De Statistique, 83, 251-275. 
Kyle MK (2006). "The Role of Firm Characteristics in Pharmaceutical Product Launches." The Rand Journal of Economics, 37, 602-618.

Kyle MK (2007). "Pharmaceutical Price Controls and Entry Strategies." The Review of Economics and Statistics, 89, 88-99.

Magazzini L, Pammolli F, Riccaboni M (2004). "Dynamic Competition in Pharmaceuticals: Patent Expiry, Generic Penetration, and Industry Structure." The Europen Journal of Health Economics, 5, 175-182.

Moreno-Torres I, Puig-Junoy J, Borrell-Arque JR (2009). "Generic Entry into a Regulated Pharmaceutical Market." Review of Industrial Organization, 34, 373-388.

Morton FMS (1999). "Entry Decisions in the Generic Pharmaceutical Industry." The RAND Journal of Economics, 30, 421-440.

Morton FMS (2000). "Barriers to Entry, Brand Advertising, and Generic Entry in the U.S. Pharmaceutical Industry." International Journal of Industrial Organization, 18, 10851104.

Papke LE, Wooldridge JM (2005). "A computational trick for delta-method standard errors." Economics Letters, 86, 413-417.

Reiffen D, Ward MR (2005). "Generic Drug Industry Dynamics." Review of Economics and Statistics, 87, 37-49.

Reiffen D, Ward MR (2007). "Branded Generics as a Strategy to Limit Cannibalization of Pharmaceutical Markets." Managerial and Decision Economics, 28, 251-265.

Saha A, Grabowski H, Birnbaum H, Greenberg P, Bizan O (2006). "Generic Competition in the U.S. Pharmaceutical Industry." International Journal of the Economics of Business, 13, 15-38.

Scherer FM (2000). The Pharmaceutical Industry. Handbook of Health Economics, I. Elsevier. Culyer, A.J., Newhouse, J.P. (Eds.), Amsterdam.

WHO (2005). "The WHO/United Nations - Pre-qualification Project."

Wilde J (2000). "Identification of Multiple Equation Probit Models with Endogenous Dummy Regressors." Economics Letters, 69, 309-312. 